\title{
Overconfidence and Trading Volume
}

\author{
Markus Glaser and Martin Weber*
}

February 26, 2004

\begin{abstract}
Theoretical models predict that overconfident investors will trade more than rational investors. We directly test this hypothesis by correlating individual overconfidence scores with several measures of trading volume of individual investors (number of trades, turnover). Approximately 3,000 online broker investors were asked to answer an internet questionnaire which was designed to measure various facets of overconfidence (miscalibration, the better than average effect, illusion of control, unrealistic optimism). The measures of trading volume were calculated by the trades of 215 individual investors who answered the questionnaire. We find that investors who think that they are above average in terms of investment skills or past performance trade more. Measures of miscalibration are, contrary to theory, unrelated to measures of trading volume. This result is striking as theoretical models that incorporate overconfident investors mainly motivate this assumption by the calibration literature and model overconfidence as underestimation of the variance of signals. The results even hold when we control for several other determinants of trading volume in a cross-sectional regression analysis. In connection with other recent findings, we conclude that the usual way of motivating and modeling overconfidence which is mainly based on the calibration literature has to be treated with caution. We argue that our findings might present a psychological foundation for the "differences of opinion" explanation of high levels of trading volume. Moreover, our way of empirically evaluating behavioral finance models - the correlation of economic and psychological variables and the combination of psychometric measures of judgment biases (such as overconfidence scores) and field data - seems to be a promising way to better understand which psychological phenomena actually drive economic behavior.
\end{abstract}

Keywords: Overconfidence, Differences of Opinion, Trading Volume, Individual Investors, Investor Behavior, Correlation of Economic and Psychological Variables, Combination of Psychometric Measures of Judgment Biases and Field Data

JEL Classification Code: D8, G1

*Markus Glaser is from the Lehrstuhl für Bankbetriebslehre, Universität Mannheim, L 5, 2, 68131 Mannheim. E-Mail: glaser@bank.BWL.uni-mannheim.de. Martin Weber is from the Lehrstuhl für Bankbetriebslehre, Universität Mannheim, L 5, 2, 68131 Mannheim and CEPR, London. E-Mail: weber@bank.BWL.uni-mannheim.de. We would like to thank Nicholas Barberis, Daniel Dorn, Martin Hellwig, Terry Odean, Klaus Röder, and seminar participants at the Universities of Mannheim, Frankfurt/Oder, Tilburg, Fribourg, the Norwegian School of Management in Oslo, Caltech, the European Summer Symposium in Financial Markets at Gerzensee, the 10th Annual Meeting of the German Finance Association in Mainz, and the 64th Annual Meeting of the American Finance Association in San Diego for valuable comments and insights. Financial Support from the Deutsche Forschungsgemeinschaft (DFG) and INQUIRE Europe is gratefully acknowledged. 


\title{
Overconfidence and Trading Volume
}

\begin{abstract}
Theoretical models predict that overconfident investors will trade more than rational investors. We directly test this hypothesis by correlating individual overconfidence scores with several measures of trading volume of individual investors (number of trades, turnover). Approximately 3,000 online broker investors were asked to answer an internet questionnaire which was designed to measure various facets of overconfidence (miscalibration, the better than average effect, illusion of control, unrealistic optimism). The measures of trading volume were calculated by the trades of 215 individual investors who answered the questionnaire. We find that investors who think that they are above average in terms of investment skills or past performance trade more. Measures of miscalibration are, contrary to theory, unrelated to measures of trading volume. This result is striking as theoretical models that incorporate overconfident investors mainly motivate this assumption by the calibration literature and model overconfidence as underestimation of the variance of signals. The results even hold when we control for several other determinants of trading volume in a cross-sectional regression analysis. In connection with other recent findings, we conclude that the usual way of motivating and modeling overconfidence which is mainly based on the calibration literature has to be treated with caution. We argue that our findings might present a psychological foundation for the "differences of opinion" explanation of high levels of trading volume. Moreover, our way of empirically evaluating behavioral finance models - the correlation of economic and psychological variables and the combination of psychometric measures of judgment biases (such as overconfidence scores) and field data - seems to be a promising way to better understand which psychological phenomena actually drive economic behavior.
\end{abstract}

Keywords: Overconfidence, Differences of Opinion, Trading Volume, Individual Investors, Investor Behavior, Correlation of Economic and Psychological Variables, Combination of Psychometric Measures of Judgment Biases and Field Data

JEL Classification Code: D8, G1 


\section{Introduction}

Trading volume appears high in financial markets. One quarter of the value of the annual worldwide trade and investment flow is traded in the foreign exchange market (including forwards, swaps, and spot transactions) each day. ${ }^{1}$ The February 2003 annualized turnover on the New York Stock Exchange (NYSE) was about $96 \%$ and the daily number of shares traded on the NYSE in the year 2002 was about 1.44 billion. The total value of trading on NYSE in the year 2002 was $\$ 10.3$ trillion U.S.. ${ }^{2}$ De Bondt and Thaler (1995) note that the high trading volume observed in financial markets "is perhaps the single most embarrassing fact to the standard finance paradigm". ${ }^{3}$

Why do investors trade such enormous quantities? Rational investors must be heterogeneous for trade to be mutually advantageous for the buyer and the seller of an asset. Differences in information alone cannot explain high levels of trading volume. This is a result of various no trade theorems, among them, for example, Milgrom and Stokey $(1982)^{4}$

Introduction of noise traders or liquidity traders who trade for reasons exogenous to models helps to circumvent no trade theorems. ${ }^{5}$ This noise or liquidity trading is not necessarily irrational. For example, endowment shocks, such as bequests or accidents, can be interpreted as liquidity trading motives. ${ }^{6}$ But common sense suggests that ascribing the high levels of trading volume mentioned above solely to noise or liquidity trading is unsatisfying. ${ }^{7}$

Two further strands of literature have emerged that are able to explain high levels of trading volume. These strands of literature are labeled as the "differences of opinion"

\footnotetext{
${ }^{1}$ Dow and Gorton (1997), p. 1026.

${ }^{2}$ See www.nyse.com.

${ }^{3}$ De Bondt and Thaler (1995), p. 392.

${ }^{4}$ See, for example, Brunnermeier (2001), pp. 30-37, for a discussion of various no trade theorems.

${ }^{5}$ See Pagano and Röell (1992), p. 680, and Brunnermeier (2001), p. 31. Shleifer and Summers (1990) survey the noise trader approach to finance.

${ }^{6}$ See, for example, Pagano and Röell (1992), p. 680.

${ }^{7}$ See also Hirshleifer (2001), p. 1564, and Wang (1998), p. 322.
} 
literature and the "overconfidence" literature. ${ }^{8}$ We now shortly discuss these two strands of literature in turn. A more comprehensive discussion will follow in Subsection 3.2.

The "differences of opinion" literature was, among others, motivated by Varian (1985, 1989). Differences of opinion can arise due to differences in prior beliefs or due to differences in the way investors interpret public information. Furthermore, it is assumed that these differences in beliefs or models for interpreting signals are common knowledge. Although everyone knows that others have different opinions, there is no adjustment of beliefs, i.e. investors "agree to disagree". Modeling differences of opinion is mainly motivated by mere plausibility: differences of opinion are present in every day life (see, for example, Harris and Raviv (1993)). The models are usually silent about the reason why there are differences of opinion in the first place. Varian (1989), Harris and Raviv (1993), and Kandel and Person (1995) show that differences of opinion help explain high levels of trading volume and that a higher degree of differences of opinion leads to a higher degree of trading volume.

The "overconfidence" literature assumes that investors overestimate the precision of information. Overconfidence models thus incorporate findings of a large set of psychological studies that are often referred to as the "calibration literature" (see, for example, Lichtenstein, Fischhoff, and Phillips (1982)). However, overconfidence models are usually motivated by a richer set of psychological results that are often summarized as overconfidence. ${ }^{9}$ These theoretical models predict that overconfident investors trade more than rational investors. De Bondt and Thaler (1995) argue that "the key behavioral factor needed to understand the trading puzzle is overconfidence" ${ }^{10}$

The discussion so far raises the following questions that our study will tackle empirically:

1. Is trading volume of an investor a function of the degree of miscalibration of the respective investor as claimed by the "overconfidence" literature?

2. Is the trading volume of an investor a function of other overconfidence measures that are often used as a motivation of overconfidence models?

\footnotetext{
${ }^{8}$ Morris (1994) shows that even in a "differences of opinion" setting no trade theorems can arise under certain conditions.

${ }^{9}$ We will discuss these further results in Subsection 3.1.

${ }^{10}$ De Bondt and Thaler (1995), p. 393.
} 
3. Are the various overconfidence measures used to motivate overconfidence models positively correlated?

4. Is there a psychological foundation of the "differences of opinion" explanation of high levels of trading volume?

We analyze these questions by correlating various overconfidence measures with measures of trading volume. A sample of approximately 3,000 individual investors with online broker accounts was asked to answer an online questionnaire which was designed to measure various facets of overconfidence, among them their degree of miscalibration. For the subgroup of 215 respondents we are able to correlate overconfidence measures and measures of trading volume which are calculated by the trades over a 51 month period.

By correlating miscalibration scores with measures of trading volume we are able to empirically test the hypothesis of overconfidence models that, the higher the degree of miscalibration (modeled as the degree of the overestimation of the precision of information), the higher the trading volume of the respective investor. In addition, we explore whether other biases which are often summarized as overconfidence and are used to motivate overconfidence models are related to trading volume. Such an analysis is necessary to guide modeling. Psychologists have found several judgment biases but it remains unclear which bias affects economic behavior or whether these biases affect economic behavior at all. These points are often put forth as a major drawback of behavioral finance models. In this vein, Fama (1998) argues that "given the demonstrated ingenuity of the theory branch of finance, and given the long litany of apparent judgment biases unearthed by cognitive psychologists, it is safe to predict that we will soon see a menu of behavioral models that can be mixed and matched to explain specific anomalies." 11 This statement shows the importance of analyzing the link or correlation between judgment biases and economic variables such as trading volume as the only way to test which bias actually influences economic behavior. Closely related is the question whether the various overconfidence biases are related, i.e. whether the overconfidence scores are positively correlated. This is important for modeling as well. Usually, only one bias is incorporated into a model. Overconfidence models assume overestimation of the precision of information whereas this assumption is, besides the calibration literature, motivated by several other findings as

\footnotetext{
${ }^{11}$ Fama (1998), p. 291.
} 
well. However, it is by no means clear that these biases are related. Furthermore, we are able to test whether there is a psychological foundation of differences of opinion models by explicitly asking investors whether they assess themselves as above average with regard to investment skills or past performance. We argue that an investor who regards himself as above average is more likely to maintain a specific opinion about the future performance of an asset even though he knows that other investors or the market hold a different opinion. Note, that this difference of opinion is the source of volume in the "differences of opinion" literature. By correlating measures of trading volume with miscalibration scores and better than average scores, we are able to empirically evaluate whether the "differences of opinion" literature or the "overconfidence" literature better explains high levels of trading volume.

Our main findings can be summarized as follows. Investors who think that they are above average trade more. Measures of miscalibration are, contrary to predictions of overconfidence models, unrelated to measures of trading volume. This result is striking as theoretical models that incorporate overconfident investors mainly motivate this assumption by the calibration literature and model overconfidence as underestimation of the variance of signals (or overestimation of their precision). These results hold even when we control for several other explanatory variables in a cross-sectional regression analysis. In connection with other recent findings, we conclude that the usual way of motivating and modeling overconfidence which is based on the calibration literature has to be treated with caution. We argue that the "differences of opinion" literature better explains high levels of trading volume when compared to the "overconfidence" literature. Furthermore, our findings present a psychological foundation for the "differences of opinion" explanation of high levels of trading volume. In addition, our way of empirically evaluating behavioral finance models - the correlation of economic and psychological variables and the combination of psychometric measures of judgment biases (such as overconfidence scores) and field data - seems to be a promising way to better understand which psychological phenomena drive economic behavior.

The rest of the paper is organized as follows. Section 2 surveys related research, especially other endeavors to test our main hypothesis and their drawbacks. Section 3 surveys overconfidence in the psychological and finance literature. Section 4 describes the data 
set and the design of our study, especially our overconfidence measures. Section 5 shows the results on the relation between measures of overconfidence and trading volume and presents several robustness checks and alternative interpretations of our results. Section 6 discusses the results and the last section concludes.

\section{Related Research}

Our analysis is related to other studies which share the common feature of correlating proxies or measures of overconfidence on the one hand and economic variables such as trading volume on the other hand.

Statman, Thorley, and Vorkink (2004) use U.S. market level data to test the hypothesis that overconfidence leads to high trading volume. They argue that after high returns subsequent trading volume will be higher as investment success increases the degree of overconfidence. ${ }^{12}$ They find an increase in trading activity after bull markets: stock trading volume (turnover) is positively related to lagged stock returns. This finding is consistent with the hypothesis that a higher degree of overconfidence leads to higher trading volume as long as high past returns are a proxy for overconfidence. Kim and Nofsinger (2003) confirm these findings using Japanese market level data. They identify stocks with varying degrees of individual ownership to test the hypothesis and discover higher monthly turnover in stocks held by individual investors during the bull market in Japan.

The proxy for overconfidence in Barber and Odean (2001) is gender. In their paper, they summarize psychological studies that find a higher degree of overconfidence among men than among women. Consequently, they partition their data set, a sample of U.S. online broker investors, on gender. They find that men trade more than women which is consistent with overconfidence models.

All the above mentioned studies share the shortcoming that overconfidence is never directly observed. Only crude proxies for overconfidence are used (past returns, gender). A direct test of the hypothesis that a higher degree of overconfidence leads to higher trading volume is the correlation of measures of overconfidence and measures of trading

\footnotetext{
${ }^{12}$ See Subsection 5.3.3 for a further discussion of dynamic overconfidence models.
} 
volume. This can be done either empirically or experimentally. Our study uses the first approach and empirically tests the above mentioned hypothesis using field data. We directly measure overconfidence via a psychological online questionnaire for a group of individual investors with online broker accounts. So we are able to directly test the hypothesis that overconfidence leads to higher trading volume by correlating measures of overconfidence with the actual trading volume of the respective investor.

Our research is thus related to (the very few) studies in economics and finance that correlate psychological data (such as measures of overconfidence) with economic variables (such as trading volume).

Fenton-O'Creevy, Nicholson, Soane, and Willman (2003) analyze the link between psychological and economic variables empirically using data on the behavior of professional traders. They measure illusion of control, one manifestation of overconfidence that we will discuss more deeply in Subsection 3.1, by a computer-based task. They find that their measure of illusion of control is negatively associated with performance as measured by traders' self-ratings, total annual earnings, and the performance assessments of a senior trader-manager. ${ }^{13}$

Biais, Hilton, Mazurier, and Pouget (2004) use the second of the above mentioned approaches and analyze experimentally whether psychological traits and cognitive biases affect trading and performance. Based on the answers of 245 subjects (students) to a psychological questionnaire they measured, among other psychological traits, the degree of overconfidence via calibration tasks. The subjects also participated in an experimental asset market. They find that overconfidence (miscalibration) reduces trading performance in the experimental asset market. However, their overconfidence measure is unrelated to trading volume. Contrary to predictions of overconfidence models, overconfident subjects do not place more orders.

\footnotetext{
${ }^{13}$ There is another study (Dorn and Huberman (2002)) which analyzes, among other things, the link between psychological variables (overconfidence) and economic variables (portfolio turnover) empirically using a transaction data set of online broker investors which is similar to ours. They measure overconfidence via a questionnaire as the difference between perceived and actual financial market knowledge and a self-attribution bias score. Their finding is that these overconfidence measures fail to explain additional variation in trading volume (p. 33). The overconfidence measures in Dorn and Huberman (2002) are, however, not based on the original psychological overconfidence studies, a point which they themselves acknowledge as they conclude in their paper that one should "conduct experimental tests of overconfidence and compare the results with actual trading behavior" (p. 34).
} 


\section{Overconfidence in the Psychological Literature and in Finance Models}

\subsection{Overconfidence in the Psychological Literature}

In the psychological literature there is no precise definition of overconfidence. There are several findings that are often summarized as overconfidence. Under this view, which is the broadest possible that can be found in the literature, overconfidence can manifest itself in the following forms: miscalibration, the better than average effect, illusion of control, and unrealistic optimism. ${ }^{14}$ We will discuss these manifestations of overconfidence in turn.

Miscalibration Studies that analyze assessments of uncertain quantities using the fractile method usually find that people's probability distributions are too tight (Lichtenstein, Fischhoff, and Phillips (1982)). For example, studies that ask people to state a 90 percent confidence interval for several uncertain quantities find that the percentage of surprises, i.e. the percentage of true values that fall outside the confidence interval, are higher than 10 percent, the percentage of surprises of a perfectly calibrated person. Other studies analyze the calibration of probability judgments. People are asked to answer questions with two answer alternatives. After that, they are asked to state the probability that their answer is correct. The usual finding is that for all questions assigned a given probability the proportion of correct answers is lower than the assigned probability (Lichtenstein, Fischhoff, and Phillips (1982)). There is still a large debate in the psychological literature over whether miscalibration is domain or task dependent or even a statistical illusion (see, for example, Gigerenzer, Hoffrage, and Kleinbölting (1991), Klayman, Soll, Gonzáles-Vallejo, and Barlas (1999), Juslin, Winman, and Olson (2000), Erev, Wallsten, and Budescu (1994)). However, the result that people form probability distributions over uncertain quantities that are too tight seems to be robust especially when people judge difficult items (see Klayman, Soll, Gonzáles-Vallejo, and Barlas (1999) or Soll and Klayman (2003)).

\footnotetext{
${ }^{14}$ Griffin and Brenner (2004), for example, argue that these concepts are linked. They present theoretical perspectives on (mis)calibration, among them the most influential perspective, optimistic overconfidence. According to the authors, the optimistic overconfidence perspective builds, for example, on the better than average effect, unrealistic optimism, and illusion of control.
} 
Better than average effect People think that they are above average. Taylor and Brown (1988) document in their survey that people have unrealistically positive views of the self. One important manifestation is that people judge themselves as better than others with regard to skills or positive personality attributes. One of the most cited examples states that $82 \%$ of a group of students rank themselves among the 30 percent of drivers with the highest driving safety (Svenson (1981)).

Illusion of control, and unrealistic optimism Langer (1975) defines illusion of control as "an expectancy of a personal success probability inappropriately higher than the objective probability would warrant". ${ }^{15}$ Closely related is the phenomenon of unrealistic optimism about future life events (Weinstein (1980)). Presson and Benassi (1996) note in their survey and meta-analysis that after Langer's article was published, illusion of control "has become a catch phrase in studies in which researchers manipulate conditions that lead people to make nonveridical judgments of control, contingency, prediction ability, etc." ${ }^{16}$ In other words, there is no precise definition of illusion of control in the psychological literature. Most of the illusion of control studies analyze how different manipulated variables such as choice, outcome sequence, task familiarity, or active involvement are related to illusion of control. Presson and Benassi (1996) stress that almost all studies do not measure the degree of control. Instead, most studies measure prediction ability or judgments of contingency so that Presson and Benassi (1996) suggest that the phrase "illusionary judgment" would better summarize the various operationalizations of illusion of control in the literature although they admit that "there is some question as to whether illusion of control researchers have examined a single underlying construct." 17

The question whether there are stable individual differences in the degree of overconfidence has long been unexplored. Recent psychological research tries to find out whether there are stable individual differences in reasoning or decision making competence (see Parker and Fischhoff (2001), Stanovich and West (1998), and Stanovich and West (2000)).

Furthermore, the question whether the above mentioned concepts - miscalibration, the

\footnotetext{
${ }^{15}$ Langer (1975), p. 311.

${ }^{16}$ Presson and Benassi (1996), p. 494.

${ }^{17}$ Presson and Benassi (1996), p. 502.
} 
better than average effect, illusion of control, and unrealistic optimism - are related is mainly unexplored. Some argue that these manifestations are related (see, for example, Taylor and Brown (1988), p. 194, and Griffin and Brenner (2004)), others argue that this need not to be the case (see, for example, Biais, Hilton, Mazurier, and Pouget (2004), p. 9), or even deny a logical link (see, for example, Hvide (2002), p. 19). Most of the studies that analyze these various facets of overconfidence try to figure out which variables or stimuli induce overconfidence and under which circumstances overconfidence is reduced. ${ }^{18}$ However, these studies do not analyze whether the above mentioned concepts are related.

\subsection{Overconfidence in Finance Models}

In this subsection, we will discuss the "differences of opinion" literature and the "overconfidence'" literature more comprehensively. Investors are willing to trade if their posterior beliefs about the value of a risky asset are different. Theoretically, there are several ways to "create" differing posterior beliefs. ${ }^{19}$

The "differences of opinion" literature was, among others, motivated by Varian (1985, 1989). Varian (1989) generalizes the mean-variance framework with diverse information of Grossman (1976) to allow for different prior probabilities. Each investor has a subjective prior distribution for the value of the risky asset. It is assumed that these prior distributions are normal but have different means. Varian (1989) finds that trading volume is entirely driven by differences of opinion. The equilibrium net trading volume of an investor only depends on the deviation of his opinion about the mean from the average opinion: The larger the differences of opinion, the larger trading volume. Harris and Raviv (1993) assume that investors have common prior beliefs and receive public information. Differences of opinion are modeled by investors interpreting this information differently, i.e. they have different likelihood functions when updating probabilities. Besides assuming differing prior beliefs, Kandel and Person (1995) model differences of opinion as follows. Investors receive a public signal which is the sum of two random variables: the liquidation

\footnotetext{
${ }^{18}$ See, for example, Presson and Benassi (1996), p. 505.

${ }^{19}$ Varian (1989), p. 6., stresses that different probability beliefs may be due to differences in information or differences in opinion. The distinction between information and opinion depends on how people modify their views when they discover that other people hold different views.
} 
value of the risky asset plus a random error term. Agents disagree about the mean of the error term. Harris and Raviv (1993) and Kandel and Person (1995) show that their respective model assumptions help explain high trading volume. Most "differences of opinion" models are silent about the reason why there are such differences of opinion. Morris (1995) and van den Steen (2001)) argue that differing prior beliefs are in line with rationality. Shiller (1999), Barberis and Thaler (2003), Hong and Stein (2003), and Diether, Malloy, and Scherbina (2002) regard differences of opinion as a form of overconfidence: investors think that their knowledge or their abilities to value stocks are better than those of other investors. ${ }^{20}$

In the remainder of this subsection, we focus on overconfidence models that help explain high levels of trading volume. Although motivated by all of its manifestations discussed in Subsection 3.1, overconfidence is exclusively modeled as overestimation of the precision of private information. Assume there is a risky asset with liquidation value $v$ which is a realization of $\tilde{v} \sim N\left(0, \sigma_{\tilde{v}}^{2}\right)$. Investors receive private signals $\tilde{s}=\tilde{v}+c \cdot \tilde{e}$ with $\tilde{e} \sim N\left(0, \sigma_{\tilde{e}}^{2}\right)$. It is assumed that $\tilde{v}$ and $\tilde{e}$ are independent such that $\tilde{s} \sim N\left(0, \sigma_{\tilde{v}}^{2}+c^{2} \cdot \sigma_{\tilde{e}}^{2}\right)$. If $c=1$, investors are rational, if $0 \leq c<1$, investors are overconfident. Conditional expectation and conditional variance of $\tilde{v}$, given the realization $s$ are (assuming that $\tilde{v}$ and $\tilde{e}$ are independent)

$$
\begin{gathered}
E[\tilde{v} \mid \tilde{s}=s]=E[\tilde{v}]+\frac{\operatorname{Cov}[\tilde{v}, \tilde{s}]}{\operatorname{Var}[\tilde{s}]}(s-E[\tilde{s}])=\frac{\sigma_{\tilde{v}}^{2}}{\sigma_{\tilde{v}}^{2}+c^{2} \cdot \sigma_{\tilde{e}}^{2}} \cdot s \\
\operatorname{Var}[\tilde{v} \mid \tilde{s}=s]=\operatorname{Var}(\tilde{v})-\frac{(\operatorname{Cov}[\tilde{v}, \tilde{s}])^{2}}{\operatorname{Var}[\tilde{s}]}=\sigma_{\tilde{v}}^{2}-\frac{\sigma_{\tilde{v}}^{4}}{\sigma_{\tilde{v}}^{2}+c^{2} \cdot \sigma_{\tilde{e}}^{2}}
\end{gathered}
$$

Overconfident investors underestimate the variance of the risky asset or overestimate its precision. Stated equivalently, their confidence intervals for the value of the risky asset are too tight. In the extreme case $(c=0)$, an investor even believes that he knows the value of the risky asset with certainty. Benos (1998), Caballé and Sákovics (2003), Kyle and Wang

\footnotetext{
${ }^{20}$ See also Odean (1998b), who argues that overconfidence in one's information is not the only manifestation of overconfidence one might expect to find in markets. He argues that traders could, instead, be overconfident about the way they interpret public information rather than about the information itself. Furthermore, he emphasizes that each investor is (over)confident in the way she interprets the information even though she "is aware of the beliefs, and perhaps even the signals" of other investors (Odean (1998b), p. 1895).
} 
(1997), Odean (1998b), and Wang (1998) incorporate this way of modeling overconfidence in different types of models such as those of Diamond and Verrecchia (1981), Hellwig (1980), Grossman and Stiglitz (1980), Kyle (1985), and Kyle (1989). ${ }^{21}$ These models differ in various dimensions. Some models assume that price takers are overconfident. Others assume that informed insiders are overconfident and act strategically because they know that they may influence the market price. Some models are one-period models, others study multiple trading rounds. However, all the above mentioned models predict that overconfidence leads to high trading volume. At the individual level, overconfident investors will trade more aggressively: The higher the degree of overconfidence of an investor, the higher her or his trading volume. Odean (1998b) calls this finding "the most robust effect of overconfidence".

Throughout the paper, we maintain the two terms "differences of opinion" literature and "overconfidence" literature. However, differences of opinion are sometimes interpreted as a form of overconfidence, and overconfidence models assume overestimation of the precision of information, which create heterogeneous (posterior) beliefs as well or make the additional assumption of differing beliefs that are common knowledge. Nevertheless, the two strands of literature are usually regarded as distinct: The "differences of opinion" literature is usually not regarded as a part of the behavioral finance literature although differences of opinion are sometimes regarded as a form of overconfidence, as described above. $^{22}$

\footnotetext{
${ }^{21}$ There are other overconfidence models that address questions like the dynamics of overconfidence, the survival of overconfident investors in markets, and the cross-section of expected returns. Examples are Daniel, Hirshleifer, and Subrahmanyam (1998), Daniel, Hirshleifer, and Subrahmanyam (2001), Hirshleifer and Luo (2001), Gervais and Odean (2001), and Wang (2001).

${ }^{22}$ The following examples highlight this point. Odean (1998b) argues that his model which assumes miscalibrated investors is, in contrast to Harris and Raviv (1993), grounded in psychological research (Odean (1998b), p. 1891). Varian (1989) admits that "differences of opinion ... can be viewed as allowing for a certain kind of irrational behavior" but "remains agnostic on this issue" as his results (trading volume is entirely driven by differences of opinion) do not hinge on "whether we want to call this "rational" or "irrational" " (Varian (1989), p. 7).
} 


\section{Data Sets, Design of the Study, and Overconfidence Measures}

The first two subsections of this section describe the various data sets we use and the design of our study. Subsection 4.3 is concerned with a possible selection bias as only 215 of approximately 3,000 investors have responded to the questionnaire. The last subsection describes the questionnaire and the various overconfidence scores we calculated using the answers of the investors.

\subsection{Data Sets}

This study is based on the combination of several data sets. The main data set consists of 563,104 buy and sell transactions of 3,079 individual investors from a German online broker in the period from January 1997 to April 2001. We considered all investors who trade via the internet, had opened their account prior to January 1997, had at least one transaction in 1997, and have an e-mail-address. ${ }^{23}$ The second data set consists of several demographic and other self-reported information (age, gender, income, investment strategy, investment experience), that was collected by the online broker at the time each investor opened her or his account. ${ }^{24}$ The third data set consists of the answers to an online questionnaire that was designed to elicit several measures of overconfidence (see Subsection 4.4). Data on the securities traded are obtained from Datastream, our fourth data source.

\subsection{Design of the Study}

All 3,079 investors received an e-mail from the online broker on Thursday, August, 2nd, 2001 with a link to the online questionnaire. 129 investors answered around the following week-end. The remaining group of investors received a second e-mail on Thursday, the 20th of September, 2001. 86 investors answered around the following weekend. So, we

\footnotetext{
${ }^{23}$ See Glaser (2003) for descriptive statistics and further details. Not necessarily all orders are placed online but all investors traded via the internet at least once in our sample period. We consider all trades by these investors, i.e. we include the trades that were placed by telephone, for example.

${ }^{24}$ See Glaser (2003) for descriptive statistics.
} 
have a response rate of $6.98 \%$, which is comparable to the response rates of similar questionnaires. ${ }^{25}$ We received the questionnaire data at the end of September, 2001, from the online broker.

In this study, we use the following measures of trading volume which are calculated by the trades of the investors: the number of stock market transactions, the number of stock market purchases, and the mean monthly stock portfolio turnover over the period from January 1997 to April 2001. We focus on stock market transactions as the models discussed in Section 3.2 make predictions about the link between overconfidence measures and stock market trading volume. The motivation for the use of the number of stock market purchases as a separate measure of trading volume is as follows. Buy and sell transactions are driven by different factors. ${ }^{26}$ An investor who wants to buy a security has the choice between thousands of stocks whereas a sell decision only requires an analysis of the usually very few stocks in the investor's own portfolio (assuming that investors do not sell short). Furthermore, when investors buy a security they have to consider the future performance of the stocks they want to buy whereas they consider future as well as past performance when they choose a security to sell. The relevance of past performance for the selling decision is the finding of some empirical and experimental studies on the disposition effect, the tendency to sell winners too early and ride losers too long. ${ }^{27}$ These studies suggest that there might be explanations for the sell decision, which are, for example, based on prospect theory (see Kahneman and Tversky (1979)). To summarize, overconfidence affects the expectations of future stock price performance. The fact that, when selling a security the effect of overconfidence is mixed with reference point dependent decision behavior of investors, justifies in our view a separate analysis of buy transactions. We conjecture that the effect of overconfidence is stronger when only buying transactions are considered.

\footnotetext{
${ }^{25}$ See, for example, Graham and Harvey (2001).

${ }^{26}$ See, for example, Odean (1999), p. 1294.

${ }^{27}$ See Shefrin and Statman (1985), Odean (1998a), and Weber and Camerer (1998) for empirical and experimental evidence on the disposition effect.
} 


\subsection{Descriptive Statistics of all Investors and the Subgroup of Respondents to the Questionnaire}

This subsection is concerned with the question of a possible sample selection bias. Table 1 compares descriptive statistics of the age, the number of transactions in all security categories (sum over the period from January 1997 to April 2001), the number of stock transactions (sum over the period from January 1997 to April 2001), the number of warrant transactions (sum over the period from January 1997 to April 2001), the average of the monthly stock portfolio value (in EUR), the average of the monthly stock portfolio turnover from January 1997 to April 2001, and the monthly stock portfolio performance (see Subsection 5.3.3 for details) for the 2,864 investors who did not answer and the 215 investors who answered the questionnaire. The table contains means and medians of these variables as well as the number of observations of the respective variable (Obs.), and the number of observations of the respective variable in percent of the number of accounts in both groups (Obs. in \% of no. of accounts). The last column presents the $p$-values of a two-sample Wilcoxon rank-sum test (Mann-Whitney test). Null hypothesis is that the two samples are from populations with the same distribution.

Table 1 shows that means and medians of all variables are similar in both groups. For example, the median age of investors in the two groups are 39 and 38, respectively. Furthermore, in both groups, about $95 \%$ of investors are male (not shown in Table 1). Non-parametric tests show that none of the differences in both groups is significant (see last column of Table 1). ${ }^{28}$ Furthermore, even the number of observations of the respective variable in percentages of the number of accounts in both groups are similar in both groups. For example, about $55 \%$ of investors in both groups trade warrants. Thus, there is no indication of a sample selection bias.

\subsection{Measures of Overconfidence}

We consider the following forms of overconfidence: miscalibration, the better than average effect, illusion of control, and unrealistic optimism. In this subsection, we will present the questions designed to measure overconfidence as well as the overconfidence measures

\footnotetext{
${ }^{28}$ See See Glaser (2003) for further descriptive statistics.
} 
obtained from the answers to these questions. In designing the questionnaire we tried to be as close as possible to the concepts and experimental tasks in the psychological literature reviewed in Subsection 3.1. Of course, we were aware of the fact that this may lead to a lower response rate.

\subsubsection{Miscalibration}

General Knowledge Questions The investors were asked to state upper and lower bounds of $90 \%$ confidence intervals to five questions concerning general knowledge:

1) number of shares traded of Adidas-Salomon AG on Thursday, 5/10/2000, in Germany.

2) number of cars sold by BMW AG in March 2001 (worldwide).

3) number of Shell-petrol stations in Germany (end of the year 2000).

4) number of private customers of Deutsche Bank AG in Europe (May 2001).

5) number of drugstores in Germany (May 2001)).

This way of measuring the degree of miscalibration is widely used. ${ }^{29} 137$ of 215 Investors answered at least one question. 114 investors answered all questions. ${ }^{30}$

If the correct answer lies outside the $90 \%$ confidence interval given by the investor we call this a surprise. For the questions which were actually answered by the respondents we calculate the percentage of surprises. Note, again, that the percentage of surprises of well calibrated investors should be $10 \%$. Table 2 summarizes the results. We use the abbreviation $\mathrm{OC}$ for the miscalibration scores as overconfidence models assume that investors are miscalibrated. The mean percentage of surprises $75 \%$. The median is even higher $(80 \%)$. These figures are much higher than $10 \%$, the expected proportion of answers outside a well calibrated $90 \%$ confidence interval. These findings are in line with

\footnotetext{
${ }^{29}$ See, for example, Klayman, Soll, Gonzáles-Vallejo, and Barlas (1999), Biais, Hilton, Mazurier, and Pouget (2004), Soll and Klayman (2003), and Subsection 3.1.

${ }^{30} 7$ investors answered 1 question, 3 investors answered 2 questions, 4 investors answered 3 questions, and 9 investors answered 4 questions.
} 
prior research. Russo and Schoemaker (1992), for example, find percentage of surprises in the range from $42 \%$ to $64 \%$. Other studies find percentages of surprises that are even closer to ours. ${ }^{31}$

Stock Market Forecasts The investors were asked to provide upper and lower bounds of $90 \%$ confidence intervals to five questions concerning stock market forecasts (Deutscher Aktienindex DAX, Nemax50 Performance Index, three German Stocks) for the end of the year 2001. ${ }^{32}$ The use of confidence interval questions is widely used to elicit subjects' probability distributions, perceptions of expected returns, and variance estimations of stock returns. ${ }^{33}$

190 of 215 Investors answered at least one question. 165 investors answered all questions. ${ }^{34}$

If the correct answer lies outside the $90 \%$ confidence interval given by the investor we call this a surprise. For the questions which were actually answered by the respondents we calculate the percentage of surprises. Again, Table 2 summarizes the results. ${ }^{35}$ The results are similar to prior research that finds percentages of surprises on exchange rate and stock price predictions from $71 \%$ to $83 \%{ }^{36}$.

\subsubsection{Better than Average Effect}

We try to measure the degree of the better than average effect using the following two questions concerning skills and performance relative to others. Investors were asked to answer the following two questions:

\footnotetext{
${ }^{31}$ See, for example, Hilton (2001), p. 42, and the references therein.

${ }^{32}$ The respondents to the first questionnaire had a forecast horizon of 21 weeks, respondents to the second questionnaire had a 14 week horizon. We also asked for the median estimate. See Subsection 5.3.2 for details.

${ }^{33}$ See, for example, Graham and Harvey (2001) and Siebenmorgen and Weber (2004) for a discussion.

${ }^{34} 4$ investors answered 1 question, 6 investors answered 2 questions, 5 investors answered 3 questions, and 10 investors answered 4 questions.

${ }^{35}$ This overconfidence measure is the only one which could be reasonably affected by the different time horizons and the terror attacks of September, 11th. Respondents to the second questionnaire have a lower percentage of surprises. This difference is only marginally significant $(p=0.0947)$. See Glaser and Weber (2003) for further details.

${ }^{36}$ See Hilton (2001), p. 42. In Subsection 5.3.2, we further analyze investors' variance estimation.
} 
1) What percentage of customers of your discount brokerage house have better skills (e.g. in the way they interpret information; general knowledge) than you at identifying stocks with above average performance in the future? (Please give a number between $0 \%$ and $100 \%$ )

2) What percentage of customers of your discount brokerage house had higher returns than you in the four-year period from January 1997 to December 2000? (Please give a number between $0 \%$ and $100 \%$ )

Table 2 summarizes the results of the answers to these two questions. We find that about half of the investors assess their skills and their abilities as above average. The median investor assesses her or his investment skills and her or his past performance as average.

For both questions, we calculate better than average scores of investor $i\left(\mathrm{BTA}_{i}\right.$ and $\left.\mathrm{BTA}_{i}\right)$ as $\frac{50-\text { answer }_{i}}{50}$ as well as the arithmetic average of these two scores $\left(\mathrm{BTA} 3_{i}\right)$. These ratios yield 0 if respondents think they are average, 1 if they think they are better than everybody else, and -1 if they think to be worse than everybody else. The mean better than average scores are positive (0.12 and 0.06 for BTA1 and BTA2, respectively). This result indicates a slight better than average effect. The high standard deviations are signs of large individual differences.

\subsubsection{Illusion of Control and Unrealistic Optimism}

We consider the following aspects that are mainly summarized as illusion of control as described in Subsection 3.1: control over (an almost) random task (such as investing in the stock market), unrealistically high personal success probability, and unrealistic optimism about the future. Nevertheless, we use the term illusion of control for all these conceptualizations in the following.

We calculate three illusion of control scores. The first illusion of control score is based on the level of agreement with the following four statements. Investors were asked to state scores from 1 (I totally agree) to 5 (I completely disagree). For each question we calculate an illusion of control score of investor $i$ as described below the respective statement.

1) I never buy stocks that will underperform in the future. 
$\mathrm{I} 1_{i}=\frac{5-\text { Answer }_{i}}{4}$. If the investor thinks she or he will never buy stocks that will underperform in the future, the score I1 is $100 \%$. If the investor completely disagrees, the score is $0 \%$.

2) I am not able to identify stocks with above average performance in the future.

$\mathrm{I} 2_{i}=\frac{\text { Answer }_{i}-1}{4}$. If the investor thinks she or he is not able to identify stocks with above average performance in the future, the score I2 is $0 \%$.

3) Buying stocks is like buying lottery tickets. Above-average performance seems to me to be more a matter of chance.

$\mathrm{I} 3_{i}=\frac{\text { Answer }_{i-1}}{4}$. If the investor thinks buying stocks is like buying lottery tickets, the score I3 is $0 \%$.

4) My forecasts of future stock prices are always true.

$\mathrm{I}_{i}=\frac{5-\text { Answer }_{i}}{4}$. If the respondent thinks her or his forecasts are always true, the score I4 is $100 \%$.

$\mathrm{IC} 1_{i}$ is the arithmetic average of these four scores.

We also asked the investors to give an estimate of their portfolio performance in the past (from January 1997 to December 2000). After that, the investors were asked to forecast the return of their portfolio in the following four-year period (from January 2001 to December 2004). The next illusion of control score is based on these estimations of the past performance and the future performance. The score of investor $i, i=1, \ldots, 215$, is calculated as follows: $\mathrm{IC}_{i}=\frac{\text { Future Performance }_{i}-\text { Past Performance }_{i}}{\max _{i=1, \ldots, 215} \mid \text { Future Performance }_{i}-\text { Past Performance }_{i} \mid}$.

The third illusion of control score IC3 is based on the comparison of the 2001 judgment of the portfolio performance in the year 2001 and the judgment of the performance of the Deutsche Aktienindex DAX in the same period. The score is calculated as follows:

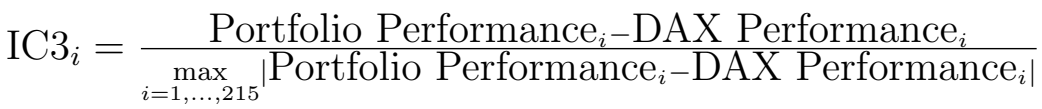

Table 2 presents summary statistics of these three scores. We find that the median person has illusion of control scores at approximately the midpoint of the respective interval. The median investor thinks her or his performance in the future will be lower than the performance in the past (IC2) and that the performance of her or his portfolio in the 
year 2001 will be as high as the performance of the Deutsche Aktienindex DAX (IC3). However, the high standard deviations indicate large individual differences.

\subsubsection{Correlation of Overconfidence Measures}

Table 3 presents correlation coefficients of seven overconfidence measures described in the previous subsections as well as the significance level of each correlation coefficient and the number of observations used in calculating the correlation coefficient. ${ }^{37}$ To conserve space we skip the variables OC3 and BTA3 which are arithmetic averages of OC1 and OC2 or BTA1 and BTA2, respectively.

The two miscalibration scores, OC1 and OC2, are significantly positively correlated $(p=0.0568)$. The Spearman rank correlation coefficient (not reported in Table 3) is 0.2036. The hypothesis that OC1 and OC2 are independent can be rejected $(p=0.0170)$. Although knowledge questions and stock market prediction questions are completely different tasks this result suggests internal validity of the two calibration concepts. We find stable individual differences in the degree of miscalibration. This finding is in line with several psychological studies (see, for example, Alba and Hutchinson (2000), Klayman, Soll, Gonzáles-Vallejo, and Barlas (1999), Pallier, Wilkinson, Danthiir, Kleitman, Knezevic, Stankov, and Roberts (2002), Soll (1996), Soll and Klayman (2003), and Stanovich and West (1998)). Usually, individual differences are especially strong when subjects are asked to state subjective confidence intervals (see, for example, Klayman, Soll, Gonzáles-Vallejo, and Barlas (1999), p. 240). Furthermore, Biais, Hilton, Mazurier, and Pouget (2004) also use ten confidence interval questions to rank people and show the psychometric validity of their miscalibration measure using the Cronbach alpha.

The two better than average scores, BTA1 and BTA2, have a correlation coefficient of 0.6786 ( $p=0.0000)$. Investors who rank themselves as above average with regard to investment skills also assess their past portfolio performance as above average when compared to other investors. This finding, again, points to psychometric internal validity of this concept. The two illusion of control scores, IC2 and IC3, are positively correlated at the $10 \%$ level. This positive correlation seems plausible given that in these two tasks es-

\footnotetext{
${ }^{37}$ Using Spearman rank correlations (not reported in Table 3) yields similar results.
} 
timation of portfolio performance or stock market performance are involved. On average, investors who think that their future four year performance will be higher than their past four year performance do believe that their own portfolio performance in the year 2001 will be higher than the performance of the German blue chip index DAX. Surprisingly, IC1 and IC3 are significantly negatively correlated. The higher the IC1 score the more people believe that they can control or predict the market. The negative correlation of IC1 and IC3 indicates that people who believe that they can predict the market think that their 2001 portfolio performance will be lower than the 2001 performance of the German blue chip index. We do not have a plausible explanation for this negative correlation. To summarize, miscalibration and the better than average effect seem to be stable individual traits whereas our scores IC1, IC2, and IC3 question whether illusion of control is a single underlying construct which is in line with Presson and Benassi (1996).

Most correlations between scores of the various facets of overconfidence are insignificant. Some are even negative. The correlation between OC2 and IC3 is significantly positive at the $1 \%$ level. This might be explained by the the fact that in both tasks stock market predictions are involved. The higher the percentage of surprises in stock market forecasts, the more an investor believes that her or his portfolio performance will be higher than the German market index DAX. The correlation coefficients between IC1 and both better than average scores are significantly negative at the $1 \%$ level. Investors who think that they are above average in terms of investment skills or past performance have a greater tendency to think that the stock market is unpredictable. We do not have an explanation for this perhaps surprising result. The lack of correlation between our overconfidence measures is consistent with findings of two recent studies that are similar to our study. Deaves, Lüders, and Luo (2003) measure miscalibration, the better than average effect, and illusion of control using our questions or a slightly changed version of our questions. Their correlation matrix also shows no significant positive correlations. Oberlechner and Osler (2003) find a negative (but statistically and economically insignificant) correlation between miscalibration and the better than average effect using a questionnaire similar to ours.

Furthermore, we find simultaneous over- and underconfidence. According to the calibration questions all investors are overconfident, whereas the median answer to the better 
than average questions is $50 \%$. Kirchler and Maciejovsky (2002) find similar results. They investigate individual overconfidence in the context of an experimental asset market with several periods. Before each period, overconfidence was measured. Participants were asked to state subjective confidence intervals for the price of the single risky asset in the next trading period as well as their subjective certainty. They also find simultaneous overand underconfidence. Depending on the method overconfidence was measured - subjective confidence intervals on the one hand and the comparison of objective accuracy and subjective certainty on the other - some participants can be classified as either overconfident or underconfident. ${ }^{38}$

\section{Overconfidence and Trading Volume: Empirical Results}

This section presents the results on the correlation of our nine overconfidence measures and three measures of trading volume. Subsection 5.1 presents correlation coefficients, Subsection 5.2 presents cross-sectional regression results. Various robustness checks, the relation between overconfidence and investors' stock return volatility estimates, and the relation between overconfidence and portfolio performance are discussed in Subsection 5.3 .

\subsection{Overconfidence and Trading Volume: Correlation Coefficients}

Table 4 presents correlation coefficients of three measures of trading volume (logarithm of the number of stock market transactions, logarithm of the number of stock market purchases, logarithm of mean monthly turnover) and the nine overconfidence measures described in Section 4.4 as well as the significance level of each correlation coefficient (in parentheses) and the number of observations used in calculating the correlation coefficient. ${ }^{39}$ The first half of the table presents correlation coefficients for all investors who

\footnotetext{
${ }^{38}$ To test the hypothesis that, the higher overconfidence the higher trading volume, not the amount or level of overconfidence but the ranking of investors is important. People often show different levels of overconfidence depending on the task or domain but the same rank-order over tasks or domains. See Jonsson and Allwood (2003), p. 561.

${ }^{39}$ We use the natural logarithm of the stock portfolio value, and the three trading volume measures as these variables are positively skewed. Tests show, that we thus avoid problems like non-normality, non-linearity, and heteroskedasticity in the cross-sectional regression analysis in Subsection 5.2. See Spanos (1986), chapter 21, especially, pp. 455-456, Davidson
} 
have responded to the questionnaire. In the second half, investors in the highest turnover quintile are excluded.

Focusing on the first half of Table 4 shows, that overconfidence as measured by calibration questions is, contrary to theory, negatively correlated with the logarithm of the number of stock market transactions and the logarithm of the number of stock market purchases. However, these correlations are insignificant. The better than average scores are significantly positively correlated with the number of stock market transactions and the number of stock purchases. The illusion of control scores are not significantly correlated with the three measures of trading volume.

Glaser (2003) shows that the stock portfolio value in the highest turnover quintile is very low. The median value is about 10,000 Euro. The fact that the median of the average stock portfolio value across months is very low in the highest turnover quintile (median of monthly turnover is $166 \%$ ) is important. Thus, we cannot dismiss the argument that these accounts are entertainment accounts that are characterized by low portfolio values and high turnover ratios so that the effect of overconfidence is swamped. ${ }^{40}$ Therefore, the second half of Table 4 shows the results when investors in the highest turnover quintile are excluded. As hypothesized, the effect of overconfidence as measured by the better than average scores BTA1, BTA2, and BTA3 are stronger. Eight out of nine correlation coefficients are positive at least at the $5 \%$ level. Three correlation coefficients are significantly positive at the $1 \%$ level. Most of the correlations between miscalibration scores and measures of trading volume remain insignificant with two exceptions. OC1 and the number of stock market purchases are now negatively correlated and OC3 and turnover are positive correlated at the $10 \%$ level.

As overconfidence models do not predict that overconfidence is the single determinant of trading volume and as overconfidence measures might be correlated with other determinants of trading volume we analyze the explanatory power of our overconfidence measures

\footnotetext{
and McKinnon (1993), chapter 14, and Atkinson (1985), pp. 80-81. We therefore use the natural logarithm of the above mentioned variables when calculating correlation coefficients. We also performed a Box-Cox transformation of variables. See Subsection 5.3.1 for details.

${ }^{40}$ Glaser (2003), Table 11, presents further characteristics of investors in the highest turnover quintile which strengthen this conjecture. For example, about $70 \%$ of investors in the highest turnover quintile actively trade warrants and only 1.39 $\%$ of these investors use their account for retirement savings.
} 
in multiple regressions in the next subsection.

\subsection{Overconfidence and Trading Volume: Cross-Sectional Regressions}

Table 6 presents regression results on the relation between the logarithm of the number of stock market transactions and several explanatory variables that are known to affect financial decision making (a gender dummy variable, age, a warrant trader dummy variable, a high risk investment strategy dummy, the logarithm of mean monthly stock portfolio value, and information in hours per week). Table 5 once again summarizes and defines dependent and independent variables of the cross-sectional regression analysis and presents their respective data source. The information variable is included to control for the level of commitment or involvement. The intuition behind this is the finding of some studies that overconfidence or illusion of control increase with the level of active involvement in a task. ${ }^{41}$ We regard the information variable as a proxy for the level of involvement in the task of investing or trading. The first regression reports the results for the subgroup of investors that has responded to the questionnaire without an overconfidence measure as explanatory variable. In each of the nine following regressions we include one overconfidence variable (Overconfidence). ${ }^{42}$ Only two overconfidence measures are significantly positively related to the number of stock market transactions at the $5 \%$ level and the 10 $\%$ level, BTA1 and BTA3. Investors who assess their skills as above average trade more stocks. However, miscalibrated investors and investors prone to the illusion of control do not exhibit a higher trading volume. Other variables that significantly affect the number of stock market transactions are the warrant trader dummy variable (positive sign) and the mean monthly stock portfolio value (positive sign). Investors who trade warrants do trade more stocks and the higher the value of the stock portfolio the higher the number of transactions. ${ }^{43}$

\footnotetext{
${ }^{41}$ See, for example, Presson and Benassi (1996), p. 496.

${ }^{42}$ Note, that we assume that overconfidence is a stable individual trait and thus constant over time. This assumption is consistent with static overconfidence models presented Subsection 3.2. Psychological studies indeed show stability over time for the concept of miscalibration (see, for example, Jonsson and Allwood (2003)). We analyze the implications of dynamic overconfidence models with a time-varying degree of overconfidence in Subsection 5.3.3. Furthermore, the standard deviations in Table 2 show that the degree of overconfidence varies markedly across individuals which makes it possible to include the overconfidence variable as explanatory variable in our regressions.

${ }^{43}$ See Glaser (2003) for further results on the general determinants of trading volume in the whole data set.
} 
Buy and sell transactions are driven by different factors. As hypothesized in Section 4.2 , the effect of overconfidence is stronger when only buy transactions are considered. Therefore, we analyze the number of purchases separately. The results show that our conjecture is confirmed. Table 7 presents regression results on the relation between the logarithm of the number of stock market purchases and several explanatory variables. Both BTA1 and BTA3 are significant at the $5 \%$ level with the expected sign. The $t$-values are, as hypothesized, higher than in Table 6 .

Table 8 presents regression results on the relation between the logarithm of mean monthly turnover and several explanatory variables. None of the nine overconfidence measures are significantly related to turnover. The main determinants of turnover are the warrant trader dummy (positive sign) and the mean monthly stock portfolio value (negative sign). The last observation is consistent with the finding that the median of the average stock portfolio value across months is very low in the highest turnover quintile.

As in Section 5.1, we now exclude investors in the highest turnover quintile and run the regressions just presented for the remaining investors. Table 9, Table 10, and Table 11 show the results. As predicted, the effect of overconfidence is much stronger. The better than average scores are significantly positive at least at the $5 \%$ level (the only exception is regression (5) in Table 11). The miscalibration and illusion of control scores have no significant impact and the signs of the coefficients are, contrary to theory, mainly negative. Furthermore, the adjusted R-squared values in Table 9, Table 10, and Table 11 are higher than in the respective table when all respondents to the questionnaire are analyzed. This stresses our previous conjecture that the level of trading volume in the highest turnover quintile are driven by factors that are unobserved. In addition, the adjusted R-squared values in Table 9, Table 10, and Table 11 are higher when the better than average scores are included when compared to the respective regression (1) in each table without an overconfidence measure as explanatory variable. Thus, the better than average scores explain additional variation of the trading volume measures. This increase in the adjusted R-squared values is higher than in the three tables that analyze all respondents to the questionnaire suggesting, again, that the accounts with the highest turnover values might be entertainment accounts.

All the results in this subsection are robust as unreported regression results show. The bet- 
ter than average scores remain significant for different sets of explanatory variables. Miscalibration scores are never significantly positive. Furthermore, most of the nine overconfidence measures are not significantly correlated with other explanatory variables. Only the better than average scores are significantly positively related to the information variable. In addition, the overconfidence measures are not significantly different for men/women, warrant-trader/non-warrant-trader, and investors that describe their investment strategy as high-risk/not high-risk. Thus, our overconfidence measures seem to capture investor characteristics that differ from other determinants of trading volume.

\subsection{Further Robustness Checks and Alternative Interpretation of the Results}

\subsubsection{Further Robustness Checks}

We also included a dummy variable that controls for the September 11 effect. This dummy variable takes the value 0 if the respondent has answered the questionnaire before September 11 and the value 1 otherwise. The coefficient of this variable is not significant and the inclusion of this variable does not alter the results.

We also interpreted the number of stock transactions and the number of stock purchases as (overdispersed) count data (see, for example, Wooldridge (2002) and Winkelmann (2003)). Overdispersion means that the variance of the number of stock transactions is larger than the mean of the number of stock transactions. In our data set, the variance of the number of stock transactions is 32,533 whereas the mean of the number of stock transactions is 105 (see Glaser (2003)). When we use appropriate regression models (Poisson regression model, negative binomial regression model), the results and conclusions are similar to the results of the ordinary least squares regressions presented in Subsection 5.2.

We used a logarithmic transformation of some regression variables in Subsection 5.2 (see footnote 39 on page 23). An applied-econometricians' rule-of-thumb to avoid problems like non-normality, non-linearity, and heteroskedasticity is to use the logarithmic transformation of positively skewed variables (see Spanos (1986)). The transformed variables are approximately normally distributed. A more formal way to transform variables is to use the Box-Cox transformation $z^{*}$ of each variable $z$ (which includes the natural logarithm 
as a special case):

$$
z^{*}=\frac{z^{\lambda}-1}{\lambda}
$$

In regressions using the Box-Cox transformation of dependent and independent variables, our basic results are even stronger.

We also calculated the percentage of surprises of investors who answered all confidence interval questions. This, of course, reduces the number of observations. When we include these overconfidence measures (instead of OC1, OC2, or OC3), the results presented in Subsections 4.4, 5.1, and 5.2 are similar.

Regressions with overconfidence measures as left-hand (dependent) variables show that it is difficult to explain the degree of overconfidence as a function of demographic variables or investor characteristics. The adjusted R-square of these regressions is about 0 .

Parametric and non-parametric tests show, that investors who think that they are above average in terms of investment skills or past performance trade significantly more when compared to investors who think that they are below average. When we partition investors in two groups based on the answers to the two BTA questions, i.e. in a group of investors who think that they are above average and in a group of investors who think that they are below average (these two groups contain approximately the same number of investors), we find that the group of investors who think that they are above average trade significantly more $(p<0.05)$.

\subsubsection{Overconfidence and Investors' Variance Estimation}

In Subsection 4.4 we presented the percentage of surprises in overconfidence questions concerning stock market forecasts of five time series (Deutscher Aktienindex DAX, Nemax50 Performance Index, three German Stocks). If the correct answer was outside the $90 \%$ confidence interval given by the investor we called this a surprise. For the questions which were actually answered by the respondents we calculated the percentage of surprises as an overconfidence measure based on stock market predictions. Note, however, that the five time series are correlated. Another and perhaps better way to analyze investors' answers 
is to calculate the variance estimation implied by their subjective confidence intervals. This is the clearest and most natural test of overconfidence models and their modeling assumption of investors underestimating the variance of stock returns. To analyze investors' volatility forecasts, we first transform these price or index value forecasts of individual $k$ into returns ${ }^{44}$ :

$r(p)_{i}^{k}=\frac{x(p)_{i}^{k}}{\text { value }_{i}^{t_{j}}}-1, \quad p \in\{0.05,0.5,0.95\}, \quad i \in\{1,2,3,4,5\}, j \in\{1,2\}, k \in\{1, \ldots, 215\}$.

$t_{1}$ indicates August 2nd, $t_{2}$ September 20th. ${ }^{45} x(p)$ denotes the $p$ fractile of the stock price or index value forecast, $r(p)$ denotes the $p$ fractile of the respective return forecast with $p \in\{0.05,0.5,0.95\}$. The five time series are denoted by $i, i \in\{1,2,3,4,5\}$.

The return volatility estimate of individual $k, k \in\{1, \ldots, 215\}$, for time series $i, i \in$ $\{1,2,3,4,5\}$, is calculated as follows (see Keefer and Bodily (1983)): ${ }^{46}$

$$
\operatorname{stddev}_{i}^{k}=\sqrt{0.185 \cdot\left(r(0.05)_{i}^{k}\right)^{2}+0.63 \cdot\left(r(0.50)_{i}^{k}\right)^{2}+0.185 \cdot\left(r(0.95)_{i}^{k}\right)^{2}-\left(\text { mean }_{i}^{k}\right)^{2}},
$$

with mean $_{i}^{k}$ as given by

$$
\text { mean }_{i}^{k}=0.185 \cdot r(0.05)_{i}^{k}+0.63 \cdot r(0.50)_{i}^{k}+0.185 \cdot r(0.95)_{i}^{k}
$$

Keefer and Bodily (1983) show numerically that equation (5) serves as a good three-point approximation of the standard deviation of a continuous random variable.

Glaser and Weber (2003) show that investors in the first group underestimate the volatility of stock returns (as measured by the standard deviation of historical returns). How-

\footnotetext{
${ }^{44}$ Some studies ask directly for returns, others ask for prices. Our method of elicitation was, among others, used by Kilka and Weber (2000).

${ }^{45}$ The exact time of response is not available. Furthermore, we do not know whether investors answered Thursday night, or on Friday, Saturday, or Sunday. Thus, we use the Thursday closing price in both groups to calculate expected returns.

${ }^{46}$ For further details, see Glaser and Weber (2003).
} 
ever, after the terror attacks of September 11, volatility forecasts are higher than before September 11. In two out of five cases, historical volatilities are overestimated.

The terror attacks of September 11 make it impossible to include the degree of the underestimation of the variance of stock returns as an overconfidence measure in our regression analysis. As an alternative, we calculate the standardized deviation from the mean volatility estimate per investor to rank investors according to their volatility estimates. For each investor group and for each time series we calculate the mean and the standard deviation of the volatility forecasts. For each investor we then calculate the standardized deviation from the mean volatility estimate by subtracting the mean volatility estimate from an investor's volatility estimate and by dividing this difference by the standard deviation of the volatility forecast. For each investor, we then calculate the average across these measures.

We find that the higher the standardized volatility forecast of an investor, the lower the percentage of surprises in stock market forecasts (OC2), i.e. the wider the confidence interval, the lower the percentage of correct answers outside the intervals. This relation is, not surprisingly, highly significant $(p=0.0000) .{ }^{47}$ The standardized volatility forecast is not significantly correlated with our trading volume measures. Including the standardized volatility forecast in our regression results yields results similar to the regressions including OC2 as an overconfidence measure. To summarize, we find no evidence that investors who make lower volatility forecasts trade more.

\subsubsection{Portfolio Performance and Overconfidence}

Up to this point in the paper we maintained the assumption that overconfidence is a stable individual trait and thus constant over time. This assumption is consistent with overconfidence models presented in Subsection 3.2. Note, that this assumption is necessary to argue that a high overconfidence score, measured at the end of the sample period, leads to high trading volume during the sample period, as overconfidence is constant through time and it does not matter when overconfidence is measured. However, there are other models as-

\footnotetext{
${ }^{47}$ The standardized volatility forecast is even significantly correlated with OC1 $(p=0.0001)$. The higher the standardized volatility forecast, the lower the percentage of surprises in knowledge questions (OC1).
} 
suming that overconfidence dynamically changes over time (see, e.g., Gervais and Odean (2001)). This modeling assumption is usually motivated by psychological studies that find biased self-attribution (see Wolosin, Sherman, and Till (1973), Langer and Roth (1975), Miller and Ross (1975), Schneider, Hastorf, and Ellsworth (1979)): People overestimate the degree to which they are responsible for their own success. In these overconfidence models, the degree of overconfidence is a function of past investment success, i.e. the higher the performance in the past the higher the degree of overconfidence at the end of the period (learning-to-be-overconfident hypothesis; Gervais and Odean (2001)). ${ }^{48}$ There is another story that involves a time-varying degree of overconfidence. Assume that (some) investors are overconfident at the start of the sample period. As a consequence, they trade more. If high trading volume is associated with low returns, the most overconfident investors at the beginning of the sample period might end up with the lowest overconfidence measures at the end of the period as a consequence of high trading volume (and low returns) during the sample period.

To empirically test these two stories, we correlate overconfidence scores with the performance of the investors in the past. Moreover, we are able to analyze whether investors who assess their investment skills or performance as above average compared to others really had above average performance in the past. Furthermore, we analyze the relation between portfolio performance and portfolio turnover.

We calculate the monthly gross portfolio performance of each investor making the following simplifying assumptions:

- We assume that all stocks are bought and sold at the end of the month.

- We ignore intra-month trading.

Barber and Odean (2000) show that these simplifying assumptions do not bias the measurement of portfolio performance.

The gross portfolio return $R_{h t}^{g r}$ of investor $h$ in month $t$ is calculated as follows:

${ }^{48}$ See Glaser, Nöth, and Weber (2004) for a further discussion of these models. 


$$
R_{h t}^{g r}=\sum_{i=1}^{S_{h t}} w_{i h t} R_{i t} \quad \text { with } \quad w_{i h t}=\frac{P_{i t} n_{i h t}}{\sum_{i=1}^{S_{h t}} P_{i t} n_{i h t}}
$$

$R_{i t}$ is the return of stock $i$ in month $t, S_{h t}$ is the number of stocks held by individual $h$ in month $t, P_{i t}$ is the price of stock $i$ at the beginning of month $t$, and $n_{i h t}$ is the number of stocks of company $i$ held by investor $h$ in month $t$. $w_{i h t}$ is the beginning-of-month- $t$ market value of the holding of stock $i$ of investor $h$ divided by the beginning-of-month- $t$ market value of the whole stock portfolio of investor $h$.

Table 12 shows the results. The cross-sectional distribution of the monthly gross returns is similar to the results in Barber and Odean (2000), Table IV, p. 791. We observe a large cross-sectional variation in the performance across investors. When we exclude investors with stock positions in 12 or fewer months, we find gross returns between $-16 \%$ and $+24 \%$ per month. On average, investors underperform relevant benchmarks (not reported in Table 12). For example, the arithmetic average monthly return of the German blue chip index DAX from January 1997 to March 2001 is 2.02\% whereas the mean gross monthly return of investors in our data set is $0.54 \%$.

We find that investors who trade more do not have higher monthly gross returns (see Figure 1). We cannot reject the hypothesis that monthly gross returns are equal in turnover quintiles (as shown in Figure 1) using a non-parametric Kruskal-Wallis test.

Furthermore, we do not find significant correlations between the monthly gross return in our 51 month period and our overconfidence measures. High returns in the past do not lead to high overconfidence measures in our questionnaire at the end of the sample period. Thus, we do not find support for the learning-to-be-overconfident hypothesis, i.e. a high degree of overconfidence as a result of past investment success. Furthermore we do not find support for the second story presented at the beginning of this subsection as we do not find a significant correlation between overconfidence and (gross) performance.

The results of this subsection might be explained by the following findings. Investors are not able to give a correct assessment of their own past realized portfolio performance. We asked the investors to give an estimate of the past realized stock portfolio performance of their account at the online broker (see also the IC2 measure in Subsection 4.4.3). The 
correlation between the assessment of past (absolute) portfolio performance and realized portfolio performance is negative (but insignificant). This finding is consistent with a result of Statman, Thorley, and Vorkink (2004) who state that "not only does that impact of past market returns on a typical security's trading activity survive the inclusion of lagged security returns in the same regression, it appears that the lagged market return impact is actually larger" (Statman, Thorley, and Vorkink (2004), p. 22). This finding is no surprise when investors have a better knowledge of market returns compared to the returns of the stocks in their own portfolio.

Moreover, investors are not able to give a correct assessment of their performance relative to others. We grouped all investors in percentiles based on their past realized stock portfolio performance. The correlation between the assessment of past portfolio performance compared to others (via percentiles; see the BTA2 measure in Subsection 4.4.2) and actual percentile is negative (but insignificant). Furthermore, the difference between the actual return percentile of the respective investor and the self-assessed percentile is positive on average (this difference is positive if an investor thinks, for example, that only $25 \%$ of the other investors had higher portfolio returns in the past even though $30 \%$ of the investors in the sample actually had higher returns). Thus, investors overestimate their relative position in terms of return percentiles.

The results of this subsection can be summarized as follows:

- Investors who trade more have, on average, the same gross monthly returns as investors who trade less.

- Investment success in the past does not lead to high overconfidence scores at the end of the sample period.

- Investors have difficulties in estimating their own past realized stock portfolio performance.

- Investors who think that they had above average performance actually did not have above average performance in the past. 


\section{Discussion}

Table 13 summarizes our main findings. We show that overconfidence as measured by calibration questions is negatively related to the number of trades. This result is inconsistent with theory but consistent with findings of Biais, Hilton, Mazurier, and Pouget (2004). Thus, the finding seems to be robust. Note, again, that overconfidence models almost exclusively model overconfidence via miscalibrated investors. Why is miscalibration not positively related to trading volume, as predicted by overconfidence models? One important point to remember is that the link between miscalibration and trading volume has never been shown or even analyzed empirically or experimentally. Biais, Hilton, Mazurier, and Pouget (2004) and our study are the only exceptions that analyze this link. Overconfidence models are motivated by psychological studies which show that people are generally miscalibrated or by empirical findings that are consistent with miscalibrated investors, such as high trading volume. However, there might be other biases that are able to explain the same empirical findings when implemented in a theoretical model. But theoretical models often incorporate only one behavioral bias. We are able to test whether different forms of overconfidence have different effects on trading volume. Information on this issue is essential for modeling purposes because we are able to rule out some forms of overconfidence as the main driving forces of trading volume which are therefore inappropriate as assumptions in theoretical models. This shows the importance of analyzing the link or correlation between judgment biases and economic variables such as trading volume as the only way to test which bias actually influences economic behavior. Scores of miscalibration obviously fail to explain trading volume.

Furthermore, there are other reasons that might explain this failure of miscalibration scores in explaining volume. In the psychological literature, there is a large debate over whether miscalibration is domain or task dependent or even a statistical illusion (see, for example, Gigerenzer, Hoffrage, and Kleinbölting (1991), Klayman, Soll, Gonzáles-Vallejo, and Barlas (1999), Juslin, Winman, and Olson (2000), Erev, Wallsten, and Budescu (1994)). In other words: The way investors are asked to state, say, the future performance of a stock, might influence the result of whether confidence intervals are too narrow or, perhaps, well calibrated. If miscalibration is not a stable individual trait or if the degree of miscalibration depends on a specific task then it is no surprise that we are unable to 
empirically confirm the hypothesis that a higher degree of miscalibration leads to higher trading volume.

Moreover, according to the usual interpretation of overconfidence measures based on calibration questions all investors are overconfident. Section 4.3 shows that investors in our sample trade a lot when compared to similar studies. ${ }^{49}$ It may be possible that all investors in our data set are overconfident and thus, all traders trade more than "normal" investors (which are not included in our data set). This interpretation is consistent with Barber and Odean (2002) who argue that online investors are generally overconfident and active traders. They analyze trading volume and performance of a group of 1,600 investors who switched from phone-based to online trading during the sample period. They find that trading volume increases and performance decreases after going online. They thus conclude that "overconfident investors were more likely to go online and once online the illusion of control and the illusion of knowledge further increased their overconfidence. Overconfidence led them to trade actively...". ${ }^{50}$ Note that we only consider investors in our sample who trade online. The Barber and Odean (2002) argument is, however, not in line with the large variation across individuals of the number of trades in our data set. It is not true that all investors in our sample trade a lot.

Our results concerning overconfidence as measured by the better than average effect are very promising. We find that investors who think that they are above average do trade more. Deaves, Lüders, and Luo (2003) measure miscalibration and the better than average effect using questions similar to ours and correlate these overconfidence scores with trading activity in an experimental asset market. They also find that people who think that they are above average trade more. ${ }^{51}$ Oberlechner and Osler (2003), p. 27, also argue and find

\footnotetext{
${ }^{49}$ Odean (1999), for example, analyzes trades of 10,000 accounts from January 1987 to December 1993. The trades file has 162,948 records in this seven year period (0.2 trades per investor per month). Our data set consists of 563,104 trades of 3079 over a period of only 51 months (3.5 trades per investor per month). Note, however, the different time periods.

${ }^{50}$ Barber and Odean (2002), p. 479.

${ }^{51}$ Furthermore, Deaves, Lüders, and Luo (2003) find that the degree of miscalibration is related to trading activity which is consistent with overconfidence models. However, experimental subjects were told that those who had exhibited higher general knowledge in the questionnaire would receive more accurate private noisy signals in the experimental asset market. Deaves, Lüders, and Luo (2003) even admit that "overconfident people will tend to think that their answers are more accurate, implying that their signals are more revealing and trade accordingly" (Deaves, Lüders, and Luo (2003), p. 8). Thus, their "miscalibration score" just captures another facet of the better than average effect.
} 
that the better than average effect, not miscalibration, explains excess trading volume using survey data from U.S. currency market professionals.

The finding that investors who think that they are above average do trade more is in line with the differences of opinion literature. Although this strand of literature is, as discussed in Subsection 3.2, usually not regarded as a part of the behavioral finance literature and although differences of opinion can be motivated rationally we propose a psychological motivation of the differences in opinions assumption. This conjecture is not completely new (see Shiller (1999), Barberis and Thaler (2003), Hong and Stein (2003), and Diether, Malloy, and Scherbina (2002)). In their model of trading in speculative markets based on differences of opinion among traders, Harris and Raviv (1993) state that, "we assume that each speculator is absolutely convinced that his or her model is correct. Indeed, each group believes the other group is basing its decision on an incorrect model (i.e. is irrational in this sense)". ${ }^{52}$ Although Harris and Raviv (1993) stress that they "maintain the assumption of rational agents", this assumption is in line with the finding that people think that they are above average in terms of investment skills. Shiller (1999), for example, argues that "if we connect the phenomenon of overconfidence with the phenomenon of anchoring, we see the origins of differences of opinion among investors, and some of the source of the high volume of trade among investors. ... Apparently, many investors do feel that they do have speculative reasons to trade often, and apparently this must have to do with some tendency for each individual to have beliefs that he or she perceives as better than others' beliefs. It is as if most people think they are above average." ${ }^{53}$.

Why do "overconfidence" models break down when they are confronted with studies that link miscalibration scores and the number of trades? Why are "differences of opinion" perhaps a better way of explaining high levels of trading volume? In both types of models, investors often receive noisy signals which are the sum of two random variables: the value of the risky asset and a random error term. Loosely speaking, "differences of opinion" models assume that investors disagree about means of random variables whereas investors in "overconfidence" models underestimate variances. Thus, both types of models are able to generate differing posterior beliefs. Perhaps, modeling disagreement about mean re-

\footnotetext{
${ }^{52}$ Harris and Raviv (1993), p. 480.

${ }^{53}$ Shiller (1999), pp. 1322-1323.
} 
turns or differing interpretation of public signals have a better foundation in documented investor behavior and investor expectations than disagreement about the variance of returns or differing posterior beliefs as a result of overestimation of the precision of private information. ${ }^{54}$ Glaser and Weber (2003) find evidence that is consistent with this conjecture. Disagreement with regard to return forecasts is higher than disagreement with regard to volatility forecasts for this group of individual investors. One conclusion of these findings is that theoretical models should create differing posteriors by assuming traders who are overconfident about the way they interpret public information or by different prior beliefs which do not converge as a result of the better than average effect rather than modeling overconfidence by overestimation of the precision of private information. Future theoretical work should further analyze the implications of differing (mean) beliefs on the one hand and underestimation of the variance of signals on the other hand.

Besides mentioning the strengths of our approach - the ability to directly test the hypothesis that a higher degree of overconfidence leads to higher trading volume - we want to discuss some possible weaknesses as well. We assume that the overconfidence scores are stable individual traits and are constant over time. This is in line with most overconfidence models mentioned in Subsection 3.2. However, psychological evidence on this issue is not unequivocal, as discussed above. Unfortunately, we were not able to verify whether our overconfidence scores are constant over time. A closely related point is that our overconfidence measures were obtained after the 51 months time period that was used to calculate the measures of trading volume of the respective investors. Another possible weakness might be the fact that we conduct the questionnaire part of our study via the internet. Internet experiments increase the variance of responses when compared to experiments in a controlled laboratory environment (Anderhub, Müller, and Schmidt (2001)). Thus, too much noise might be a possible reason why we are unable to prove a link between miscalibration scores and measures of trading volume. We note, however, that Biais, Hilton, Mazurier, and Pouget (2004) find results similar to ours in a controlled environment. Furthermore, if we find a significant effect despite the noise inherent in internet questionnaires, such as in the case of the better than average scores, we can be

\footnotetext{
${ }^{54}$ Note that underestimation of the variance of signals also creates heterogeneity of conditional means (differing posterior beliefs; see equation (1)) that are driven by information (signal realizations), not by differing opinions concerning the mean of the prior (such as, for example, in Varian (1989)).
} 
very confident about the presence of this link in reality.

\section{Conclusion}

The contribution of this paper is to measure overconfidence of a group of online broker investors in various dimensions (miscalibration, the better than average effect, illusion of control, unrealistic optimism) and to analyze whether these overconfidence measures are significantly related with trading volume of individual investors.

One implication of our study is that one has to be careful when deriving theoretical assumptions from psychological experiments unrelated to financial tasks. It is important to specify what kind of overconfidence - miscalibration, the better than average effect, or illusion of control - may be influencing trading behavior. Hirshleifer (2001), for example, argues that "it is often not obvious how to translate preexisting evidence from psychological experiments into assumptions about investors in real financial settings. Routine experimental testing of the assumptions and conclusions of asset-pricing theories is needed to guide modeling." ${ }^{55}$. We are able to contribute to this endeavor.

We find that investors who think that they are above average trade more. One of the most striking results of our study is that overconfidence, as measured by calibration questions, is unrelated to trading volume. This result seems to be robust as Biais, Hilton, Mazurier, and Pouget (2004) report similar findings. These results are even more important as theoretical models that incorporate overconfident investors mainly motivate this assumption by the calibration literature and model overconfidence as underestimation of the variance of signals (or overestimation of their precision), i.e. by too tight confidence intervals. In connection with other recent findings, we conclude that the usual way of motivating and modeling overconfidence which is mainly based on the calibration literature has to be treated with caution.

There are several suggestions for future research. We measure various facets of overconfidence: miscalibration, the better than average effect, illusion of control, and unrealistic optimism. Numerous studies suggest or argue, at least implicitly, that these manifesta-

\footnotetext{
${ }^{55}$ Hirshleifer (2001), p. 1577.
} 
tions of overconfidence are related. In other words: answers to experimental tasks should be positively correlated. Our study is a hint that this need not be the case. Future research should further analyze whether overconfidence is a robust phenomenon across several tasks that are often assumed to be related. Furthermore, our way of empirically evaluating behavioral finance models - the correlation of economic and psychological variables and the combination of psychometric measures of judgment biases (such as overconfidence scores) and field data - seems to be a promising way to better understand which psychological phenomena drive economic behavior. This empirical methodology should be routinely used to guide modeling. 


\section{References}

Alba, Joseph W., and J. Wesley Hutchinson, 2000, Knowledge calibration: What consumers know and what they think they know, Journal of Consumer Research 27, 123156.

Anderhub, Vital, Rudolf Müller, and Carsten Schmidt, 2001, Design and evaluation of an economic experiment via the internet, Journal of Economic Behavior and Organization $46,227-247$.

Atkinson, A.C., 1985, Plots, Transformations, and Regression (Clarendon Press).

Barber, Brad M., and Terrance Odean, 2000, Trading is hazardous to your wealth: The common stock investment performance of individual investors, Journal of Finance 55, $773-806$.

— , 2001, Boys will be boys: Gender, overconfidence, and common stock investment, Quarterly Journal of Economics 116, 261-292.

— 2002, Online investors: Do the slow die first?, Review of Financial Studies 15, $455-487$.

Barberis, Nicholas, and Richard Thaler, 2003, Behavioral finance, in George M. Constantinides, Milton Harris, and Rene M. Stulz, ed.: Handbook of the Economics of Finance, pp. 1053-1123 (North Holland).

Benos, Alexandros V., 1998, Aggressiveness and survival of overconfident traders, Journal of Financial Markets 1, 353-383.

Biais, Bruno, Denis Hilton, Karine Mazurier, and Sébastien Pouget, 2004, Judgmental overconfidence, self-monitoring and trading performance in an experimental financial market, Review of Economic Studies pp. - forthcoming.

Brunnermeier, Markus K., 2001, Asset Pricing under Asymmetric Information: Bubbles, Crashes, Technical Analysis, and Herding (Oxford University Press).

Caballé, Jordi, and József Sákovics, 2003, Speculating against an overconfident market, Journal of Financial Markets 6, 199-225. 
Daniel, Kent, David Hirshleifer, and Avanidhar Subrahmanyam, 1998, Investor psychology and security market under- and overreactions, Journal of Finance 53, 1839-1885.

— , 2001, Overconfidence, arbitrage, and equilibrium asset pricing, Journal of Finance 56, 921-965.

Davidson, Russell, and James G. MacKinnon, 1993, Estimation and Inference in Econometrics (Oxford University Press).

Deaves, Richard, Erik Lüders, and Rosemary Luo, 2003, An experimental test of the impact of overconfidence and gender on trading activity, Working paper, McMaster University.

DeBondt, Werner F.M., and Richard H. Thaler, 1995, Financial decision making in markets and firms: A behavioral perspective, in R. A. Jarrow, V. Maksimovic, and W. T. Ziemba, ed.: Handbooks in Operations Research and Management Science, Volume 9, Finance, pp. 385-410 (Elsevier).

Diamond, Douglas W., and Robert E. Verrecchia, 1981, Information aggregation in a noisy rational expectations economy, Journal of Financial Economics 9, 221-235.

Diether, Karl B., Christopher J. Malloy, and Anna Scherbina, 2002, Differences of opinion and the cross section of stock returns, Journal of Finance 57, 2113-2141.

Dorn, Daniel, and Gur Huberman, 2002, Who trades?, Working paper, Columbia University.

Dow, James, and Gary Gorton, 1997, Noise trading, delegated portfolio management, and economic welfare, Journal of Political Economy 105, 1024-1050.

Erev, Ido, Thomas S. Wallsten, and David V. Budescu, 1994, Simultaneous over- and underconfidence: The role of error in judgment processes, Psychological Review 101, $519-528$.

Fama, Eugene F., 1998, Market efficiency, long-term returns, and behavioral finance, Journal of Financial Economics 49, 283-306.

Fenton-O'Creevy, Mark, Nigel Nicholson, Emma Soane, and Paul Willman, 2003, Trading on illusions: unrealistic perceptions of control and trading performance, Journal of Occupational and Organizational Psychology 76, 53-68. 
Gervais, Simon, and Terrance Odean, 2001, Learning to be overconfident, Review of Financial Studies 14, 1-27.

Gigerenzer, Gerd, Ulrich Hoffrage, and Heinz Kleinbölting, 1991, Probabilistic mental models: A brunswikian theory of confidence, Psychological Review 98, 506-528.

Glaser, Markus, 2003, Online broker investors: Demographic information, investment strategy, portfolio positions, and trading activity, SFB 504 discussion paper 03-18, University of Mannheim.

— — Markus Nöth, and Martin Weber, 2004, Behavioral finance, in Derek Koehler, and Nigel Harvey, ed.: Blackwell Handbook of Judgment and Decision Making (Blackwell) forthcoming.

Glaser, Markus, and Martin Weber, 2003, September 11 and stock return expectations of individual investors, SFB 504 discussion paper 03-17, University of Mannheim.

Graham, John R., and Campbell R. Harvey, 2001, Expectations of equity risk premia, volatility, and asymmetry from a corporate finance perspective, NBER Working paper 8678.

Griffin, Dale, and Lyle Brenner, 2004, Perspectives on probability judgment calibration, in Derek Koehler, and Nigel Harvey, ed.: Blackwell Handbook of Judgment and Decision Making (Blackwell) forthcoming.

Grossman, Sanford J., 1976, On the efficiency of competitive stock markets where traders have diverse information, Journal of Finance 31, 573-585.

— , and Joseph E. Stiglitz, 1980, On the impossibility of informationally efficient markets, American Economic Review 70, 393-408.

Harris, Milton, and Artur Raviv, 1993, Differences of opinion make a horse race, Review of Financial Studies 6, 473-506.

Hellwig, Martin F., 1980, On the aggregation of information in competitive markets, Journal of Economic Theory 22, 477-498.

Hilton, Denis J., 2001, The psychology of financial decision-making: Applications to trading, dealing, and investment analysis, Journal of Psychology and Financial Markets 2, $37-53$. 
Hirshleifer, David, 2001, Investor psychology and asset pricing, Journal of Finance 56, $1533-1597$.

— , and Guo Ying Luo, 2001, On the survival of overconfident traders in a competitive securities market, Journal of Financial Markets 4, 73-84.

Hong, Harrison, and Jeremy C. Stein, 2003, Differences of opinion, short-sales constraints and market crashes, Review of Financial Studies 16, 487-525.

Hvide, Hans K., 2002, Pragmatic beliefs and overconfidence, Journal of Economic Behavior and Organization 48, 15-28.

Jonsson, Anna-Carin, and Carl Martin Allwood, 2003, Stability and variability in the realism of confidence judgments over time, content domain, and gender, Personality and Individual Differences 34, 559-574.

Juslin, Peter, Anders Winman, and Henrik Olson, 2000, Naive empiricism and dogmatism in confidence research: A critical examination of the hard-easy effect, Psychological Review 107, 384-396.

Kahneman, Daniel, and Amos Tversky, 1979, Prospect theory: An analysis of decision under risk, Econometrica 47, 263-292.

Kandel, Eugene, and Neil D. Pearson, 1995, Differential interpretation of public signals and trade in speculative markets, Journal of Political Economy 103, 831-872.

Keefer, Donald L., and Samuel E. Bodily, 1983, Three-point approximations for continuous random variables, Management Science 29, 595-609.

Kilka, Michael, and Martin Weber, 2000, Home bias in international stock return expectations, Journal of Psychology and Financial Markets 1, 176-192.

Kim, Kenneth A., and John R. Nofsinger, 2003, The behavior and performance of individual investors in Japan, Working paper.

Kirchler, Erich, and Boris Maciejovsky, 2002, Simultaneous over- and underconfidence: Evidence from experimental asset markets, Journal of Risk and Uncertainty 25, 65-85.

Klayman, Joshua, Jack B. Soll, Claudia Gonzáles-Vallejo, and Sema Barlas, 1999, Overconfidence: It depends on how, what, and whom you ask, Organizational Behavior and Human Decision Processes 79, 216-247. 
Kyle, Albert S., 1985, Continuous auctions and insider trading, Econometrica 53, 13151336.

— , 1989, Informed speculation with imperfect competition, Review of Economic Studies 56, 317-356.

, and F. Albert Wang, 1997, Speculation duopoly with agreement to disagree: Can overconfidence survive the market test?, Journal of Finance 52, 2073-2090.

Langer, Ellen J., 1975, The illusion of control, Journal of Personality and Social Psychology $32,311-328$.

_ and Jane Roth, 1975, Heads I win, tail it's chance: The illusion of control as a function of the sequence of outcomes in a purely chance task, Journal of Personaliy and Social Psychology 32, 951-955.

Lichtenstein, Sarah, Baruch Fischhoff, and Lawrence D. Phillips, 1982, Calibration of probabilities: The state of the art to 1980, in Daniel Kahneman, Paul Slovic, and Amos Tversky, ed.: Judgment under uncertainty: Heuristics and Biases, pp. 306-334 (Cambridge University Press).

Milgrom, Paul, and Nancy Stokey, 1982, Information, trade and common knowledge, Journal of Economic Theory 26, 17-27.

Miller, Dale T., and Michael Ross, 1975, Self-serving biases in the attribution of causality: Fact or fiction?, Psychological Bulletin 82, 213-225.

Morris, Stephen, 1994, Trade with heterogeneous prior beliefs and asymmetric information, Econometica 62, 1327-1347.

— 1995, The common prior assumption in economic theory, Economics and Philosophy 11, 227-253.

Oberlechner, Thomas, and Carol L. Osler, 2003, Overconfidence in currency markets, Working paper.

Odean, Terrance, 1998a, Are investors reluctant to realize their losses?, Journal of Finance 53, 1775-1798.

— 1998b, Volume, volatility, price, and profit when all traders are above average, Journal of Finance 53, 1887-1934. 
— 1999, Do investors trade too much?, American Economic Review 89, 1279-1298.

Pagano, Marco, and Alisa Röell, 1992, Trading volume, in Peter Newman, John Eatwell, and Murray Milgate, ed.: The New Palgrave Dictionary of Money and Finance, pp. 679-683 (Macmillan).

Pallier, Gerry, Rebecca Wilkinson, Vanessa Danthiir, Sabina Kleitman, Goran Knezevic, Lazar Stankov, and Richard D. Roberts, 2002, The role of individual differences in the accuracy of confidence judgments, Journal of General Psychology 129, 257-299.

Parker, Andrew M., and Baruch Fischhoff, 2001, Decision-making competence: An individual-differences approach, Working paper.

Presson, Paul K., and Victor A. Benassi, 1996, Illusion of control: A meta-analytic review, Journal of Social Behavior and Personality 11, 493-510.

Russo, J. Edward, and Paul J. H. Schoemaker, 1992, Managing overconfidence, Sloan Management Review 33, 7-17.

Schneider, David J., Albert H. Hastorf, and Phoebe C. Ellsworth, 1979, Person Perception (Addison-Wesley).

Shefrin, Hersh, and Meir Statman, 1985, The disposition to sell winners too early and ride losers too long: Theory and evidence, Journal of Finance 40, 777-790.

Shiller, Robert J., 1999, Human behavior and the efficiency of the financial system, in J.B. Taylor, and M. Woodford, ed.: Handbook of Macroeconomics, pp. 1305-1340 (Elsevier Science).

Shleifer, Andrei, and Lawrence H. Summers, 1990, The noise trader approach to finance, Journal of Economic Perspectives 4, 19-33.

Siebenmorgen, Niklas, and Martin Weber, 2004, The influence of different investment horizons on risk behavior, Journal of Behavioral Finance pp. - forthcoming.

Soll, Jack B., 1996, Determinants of overconfidence and miscalibration: The roles of random error and ecological structure, Organizational Behavior and Human Decision Processes $65,117-137$.

— , and Joshua Klayman, 2003, Overconfidence in interval estimates, Working paper, INSEAD and University of Chicago. 
Spanos, Aris, 1986, Statistical foundations of econometric modelling (Cambridge University Press).

Stanovich, Keith E., and Richard F. West, 1998, Individual differences in rational thought, Journal of Experimental Psychology 127, 161-188.

— , 2000, Individual differences in reasoning: Implications for the rationality debate, Behavioral and Brain Sciences 23, 645-726.

Statman, Meir, Steven Thorley, and Keith Vorkink, 2004, Investor overconfidence and trading volume, Working paper.

Svenson, Ola, 1981, Are we all less risky and more skillful than our fellow drivers?, Acta Psychologica 47, 143-148.

Taylor, Shelley S., and Jonathan D. Brown, 1988, Illusion and well being: A social psychology perspective on mental health, Psychological Bulletin 103, 193-210.

van der Steen, Eric J., 2001, Essays on the managerial implications of differing priors, Ph.D. Thesis, Graduate School of Business, Stanford University.

Varian, Hal R., 1985, Divergence of opinion in complete markets: A note, Journal of Finance 40, 309-317.

— 1989, Differences of opinion in financial markets, in Courtenay C. Stone, ed.: Financial Risk: Theory, Evidence, and Implications, pp. 3-37 (Kluwer).

Wang, F. Albert, 1998, Strategic trading, asymmetric information and heterogeneous prior beliefs, Journal of Financial Markets 1, 321-352.

— , 2001, Overconfidence, investor sentiment, and evolution, Journal of Financial Intermediation 10, 138-170.

Weber, Martin, and Colin Camerer, 1998, The disposition effect in securities trading: Experimental evidence, Journal of Economic Behavior and Organization 33, 167-184.

Weinstein, Neil D., 1980, Unrealistic optimism about future life events, Journal of Personality and Social Psychology 39, 806-820.

Winkelmann, Rainer, 2003, Econometric analysis of count data (Springer). 
Wolosin, R.J., S.J. Sherman, and A. Till, 1973, Effects of cooperation and competition on responsibility attribution after success and failure, Journal of Experimental Social Psychology 9, 220-235.

Wooldridge, Jeffrey M., 2002, Econometric Analysis of Cross Section and Panel Data (MIT Press). 
Table 1: Descriptive Statistics: Investors who Answered versus Investors who did not Answer the Questionnaire

This table compares descriptive statistics of the age, the number of transactions in all security categories (sum over the period from January 1997 to April 2001), the number of stock transactions (sum over the period from January 1997 to April 2001), the number of warrant transactions (sum over the period from January 1997 to April 2001), the average of the monthly stock portfolio value (in EUR), the average of the monthly stock portfolio turnover from January 1997 to April 2001, and the monthly stock portfolio performance (see Subsection 5.3.3 for details) for the 2,864 investors who did not answer and the 215 investors who answered the questionnaire. The table contains means and medians of these variables as well as the number of observations of the respective variable (Obs.), and the number of observations of the respective variable in percent of the number of accounts in both groups (Obs. in \% of no. of accounts). The last column presents the $p$-values of a two-sample Wilcoxon rank-sum test (Mann-Whitney test). Null hypothesis is that the two samples are from populations with the same distribution.

\begin{tabular}{|c|c|c|c|c|}
\hline & & $\begin{array}{l}\text { Investors who } \\
\text { did not answer } \\
\text { questionnaire }\end{array}$ & $\begin{array}{l}\text { Investors who } \\
\text { answered } \\
\text { questionnaire }\end{array}$ & $\begin{array}{c}p \text {-value } \\
\text { (Mann-Whitney test) }\end{array}$ \\
\hline No. of accounts & & 2,864 & 215 & \\
\hline \multirow[t]{4}{*}{ Age } & Mean & 40.92 & 40.02 & \multirow[t]{4}{*}{0.2942} \\
\hline & Median & 39 & 38 & \\
\hline & Obs. & 2,369 & 183 & \\
\hline & Obs. in $\%$ of no. of accounts & 82.72 & 85.12 & \\
\hline \multirow[t]{4}{*}{ Transactions } & Mean & 184.89 & 156.17 & \multirow[t]{4}{*}{0.5621} \\
\hline & Median & 103 & 105 & \\
\hline & Obs. & 2,864 & 215 & \\
\hline & Obs. in $\%$ of no. of accounts & 100.00 & 100.00 & \\
\hline \multirow[t]{4}{*}{ Stock transactions } & Mean & 106.37 & 92.87 & \multirow[t]{4}{*}{0.9422} \\
\hline & Median & 54 & 52 & \\
\hline & Obs. & 2,793 & 205 & \\
\hline & Obs. in $\%$ of no. of accounts & 97.52 & 95.35 & \\
\hline \multirow[t]{4}{*}{ Warrant transactions } & Mean & 88.99 & 69.81 & \multirow[t]{4}{*}{0.8194} \\
\hline & Median & 27 & 29 & \\
\hline & Obs. & 1530 & 120 & \\
\hline & Obs. in $\%$ of no. of accounts & 53.42 & 55.81 & \\
\hline \multirow{4}{*}{$\begin{array}{l}\text { Stock portfolio } \\
\text { value }\end{array}$} & Mean & 36590.83 & 37061.01 & \multirow[t]{4}{*}{0.5614} \\
\hline & Median & 15629.70 & 15887.10 & \\
\hline & Obs. & 2,762 & 202 & \\
\hline & Obs. in $\%$ of no. of accounts & 96.44 & 93.95 & \\
\hline \multirow{4}{*}{$\begin{array}{l}\text { Stock portfolio } \\
\text { turnover }\end{array}$} & Mean & 1.37 & 1.21 & \multirow[t]{4}{*}{0.9692} \\
\hline & Median & 0.33 & 0.33 & \\
\hline & Obs. & 2,675 & 199 & \\
\hline & Obs. in $\%$ of no. of accounts & 93.40 & 92.56 & \\
\hline \multirow{4}{*}{$\begin{array}{l}\text { Stock portfolio } \\
\text { performance }\end{array}$} & Mean & 0.0056 & 0.0030 & \multirow[t]{4}{*}{0.4538} \\
\hline & Median & 0.0057 & 0.0053 & \\
\hline & Obs. & 2,598 & 195 & \\
\hline & Obs. in $\%$ of no. of accounts & 90.71 & 90.70 & \\
\hline
\end{tabular}




\section{Table 2: Overconfidence Variables: Descriptive Statistics}

This table presents descriptive statistics of the overconfidence measures defined in Subsection 4.4 as well as the intervals that contain the respective measures. For all overconfidence measures a higher value indicates a higher degree of overconfidence. The table presents mean, median, standard deviation (std.dev.), and the number of investors who responded to the respective question (no. Obs.).

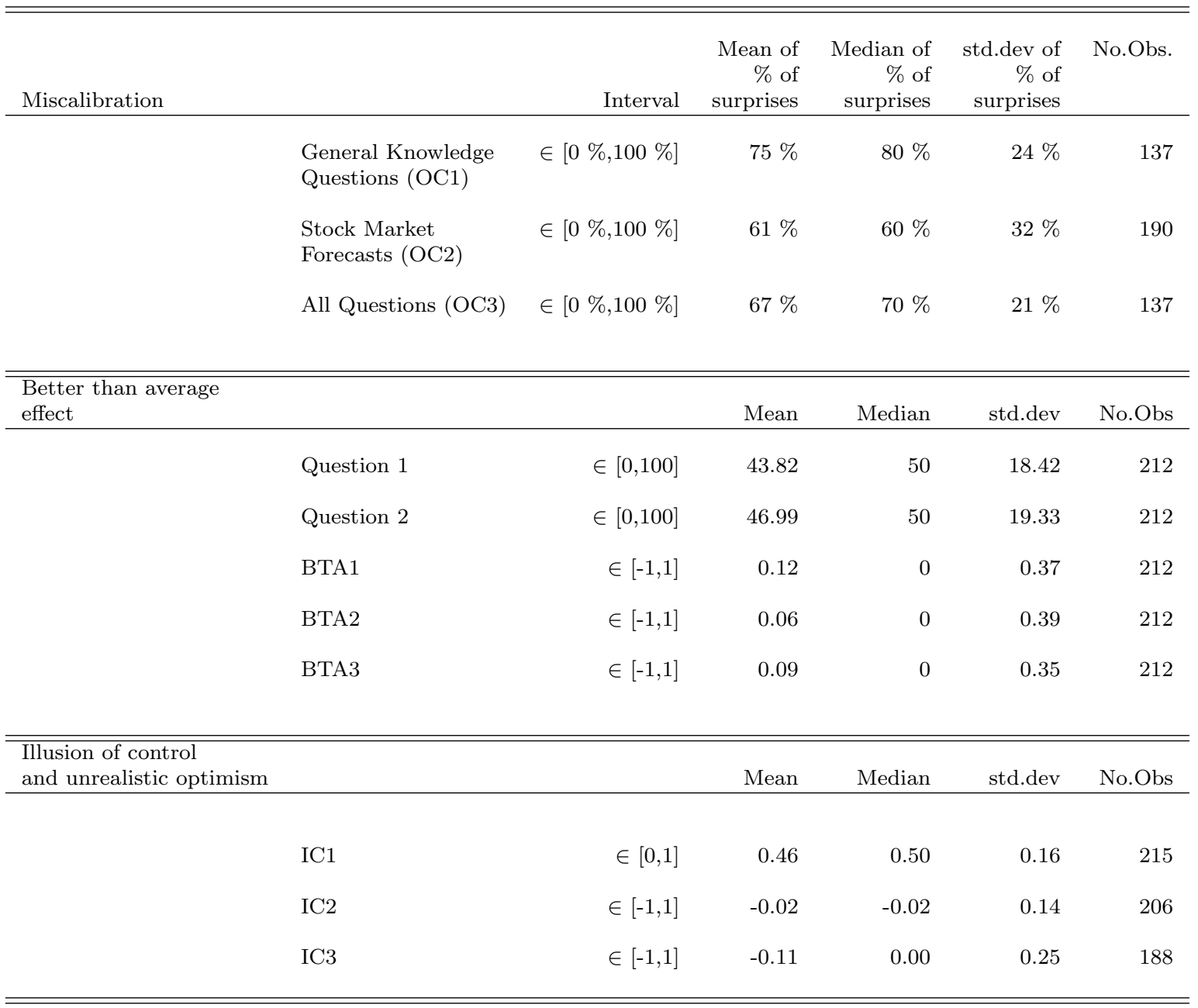




\section{Table 3: Correlation of Overconfidence Variables}

This table presents pairwise correlations between seven of our overconfidence measures described in Subsection 4.4 as well as the significance level of each correlation coefficient (in parentheses) and the number of observations used in calculating the correlation coefficient. To conserve space we skip the variables $\mathrm{OC} 3$ and BTA3 which are arithmetic averages of $\mathrm{OC} 1$ and $\mathrm{OC} 2$ or BTA1 and BTA2, respectively. $*$ indicates significance at $10 \%$; *** indicates significance at $1 \%$.

\begin{tabular}{|c|c|c|c|c|c|c|c|}
\hline & $\mathrm{OC} 1$ & $\mathrm{OC} 2$ & BTA1 & BTA2 & IC1 & IC2 & IC3 \\
\hline \multirow[t]{2}{*}{ OC1 } & 1 & & & & & & \\
\hline & 137 & & & & & & \\
\hline \multirow[t]{2}{*}{$\mathrm{OC} 2$} & $\begin{array}{c}0.1631 \\
(0.0568)^{*}\end{array}$ & 1 & & & & & \\
\hline & 137 & 190 & & & & & \\
\hline \multirow[t]{2}{*}{ BTA1 } & $\begin{array}{c}-0.0402 \\
(0.6411)\end{array}$ & $\begin{array}{l}-0.0867 \\
(0.2345)\end{array}$ & & & & & \\
\hline & 137 & 190 & 212 & & & & \\
\hline \multirow[t]{2}{*}{ BTA2 } & $\begin{array}{c}0.1487 \\
(0.0828)^{*}\end{array}$ & $\begin{array}{c}-0.0058 \\
(0.9363)\end{array}$ & $\begin{array}{c}0.6785 \\
(0.0000)^{* * *}\end{array}$ & & & & \\
\hline & 137 & 190 & 212 & 212 & & & \\
\hline \multirow[t]{2}{*}{ IC1 } & $\begin{array}{l}-0.0513 \\
(0.5516)\end{array}$ & $\begin{array}{c}-0.0234 \\
(0.7491)\end{array}$ & $\begin{array}{c}-0.2241 \\
(0.0010)^{* * *}\end{array}$ & $\begin{array}{c}-0.1865 \\
(0.0065)^{* * *}\end{array}$ & 1 & & \\
\hline & 137 & 190 & 212 & 212 & 215 & & \\
\hline \multirow[t]{2}{*}{ IC2 } & $\begin{array}{l}-0.0454 \\
(0.6021)\end{array}$ & $\begin{array}{c}0.0828 \\
(0.2612)\end{array}$ & $\begin{array}{c}-0.0902 \\
(0.1994)\end{array}$ & $\begin{array}{c}-0.2024 \\
(0.0037)^{* * *}\end{array}$ & $\begin{array}{c}0.0604 \\
(0.3883)\end{array}$ & 1 & \\
\hline & 134 & 186 & 204 & 204 & 206 & 206 & \\
\hline \multirow[t]{2}{*}{ IC3 } & $\begin{array}{l}-0.0153 \\
(0.8602)\end{array}$ & $\begin{array}{c}0.2342 \\
(0.0013)^{* * *}\end{array}$ & $\begin{array}{c}0.0485 \\
(0.5082)\end{array}$ & $\begin{array}{c}0.1134 \\
(0.1212)\end{array}$ & $\begin{array}{c}-0.1915 \\
(0.0085)^{* * *}\end{array}$ & $\begin{array}{c}0.1385 \\
(0.0594)^{*}\end{array}$ & 1 \\
\hline & 135 & 186 & 188 & 188 & 188 & 186 & 188 \\
\hline
\end{tabular}




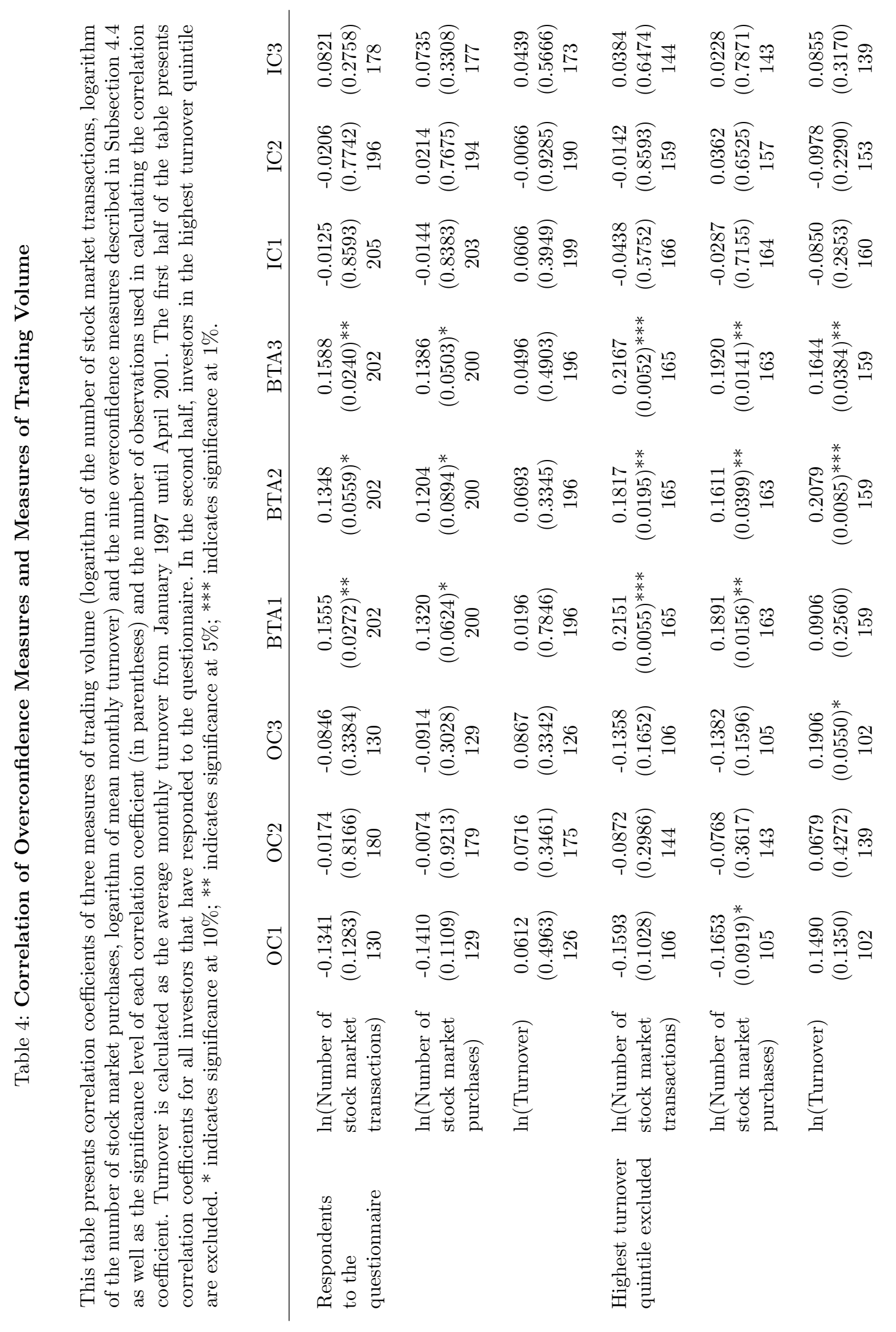




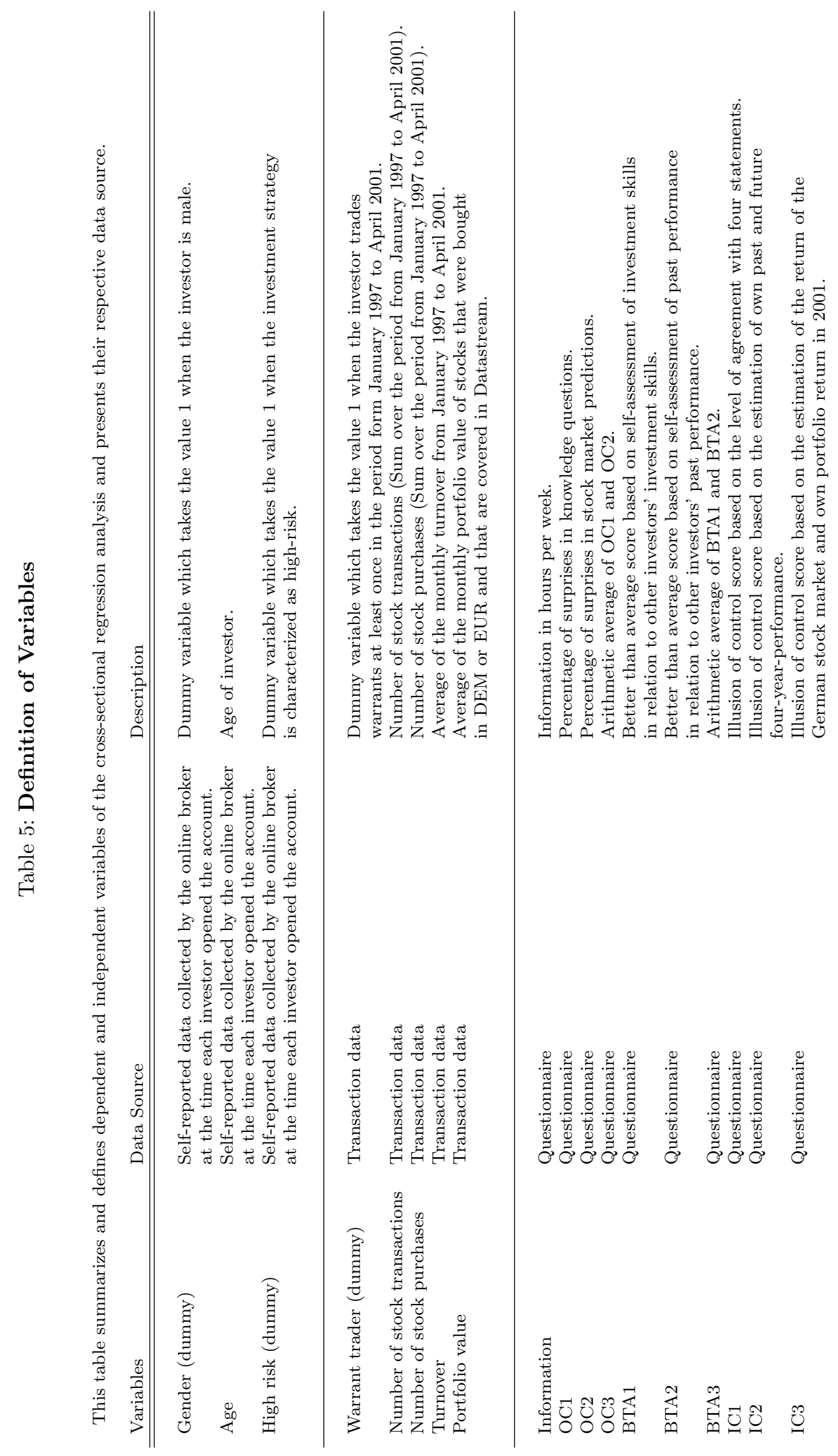




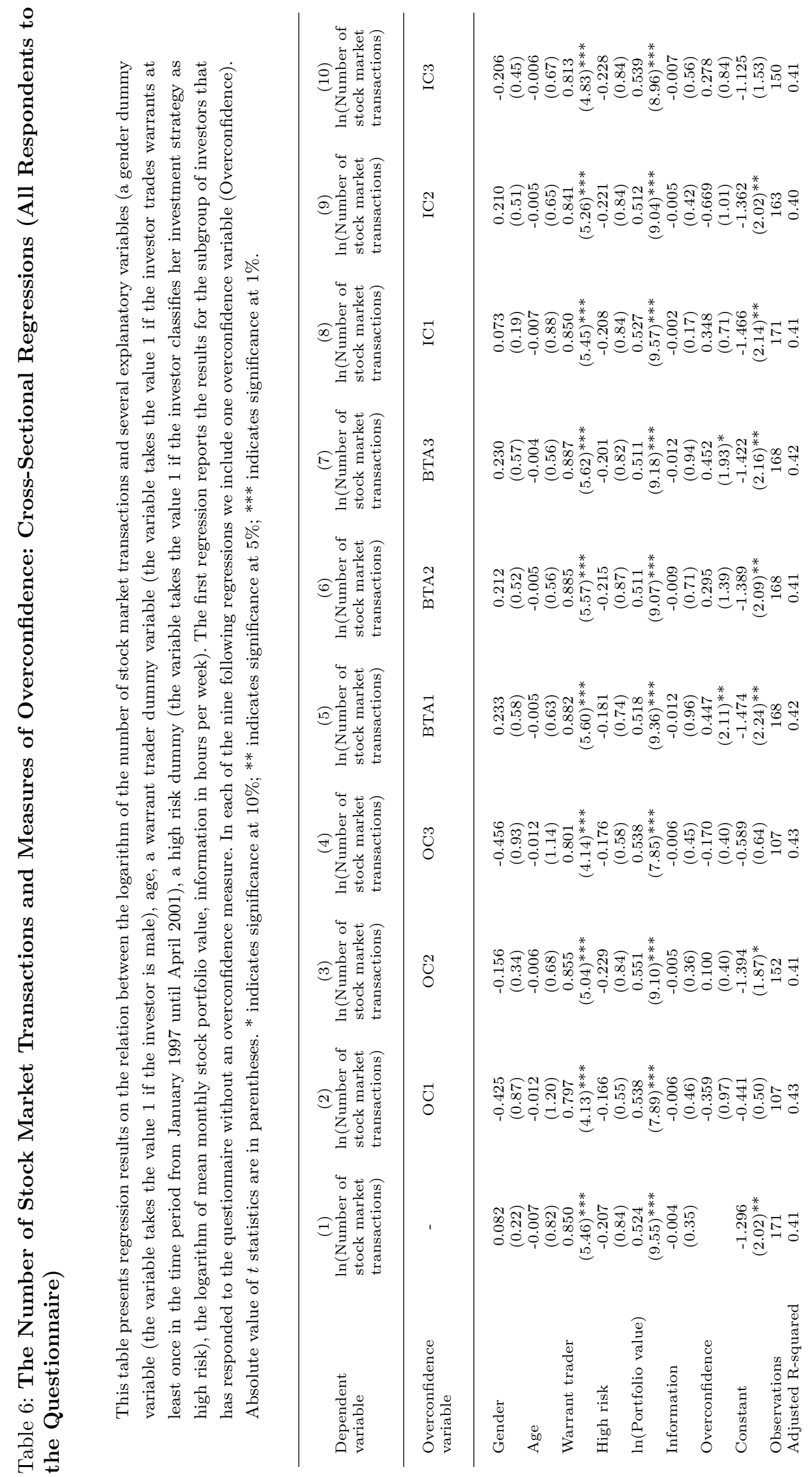




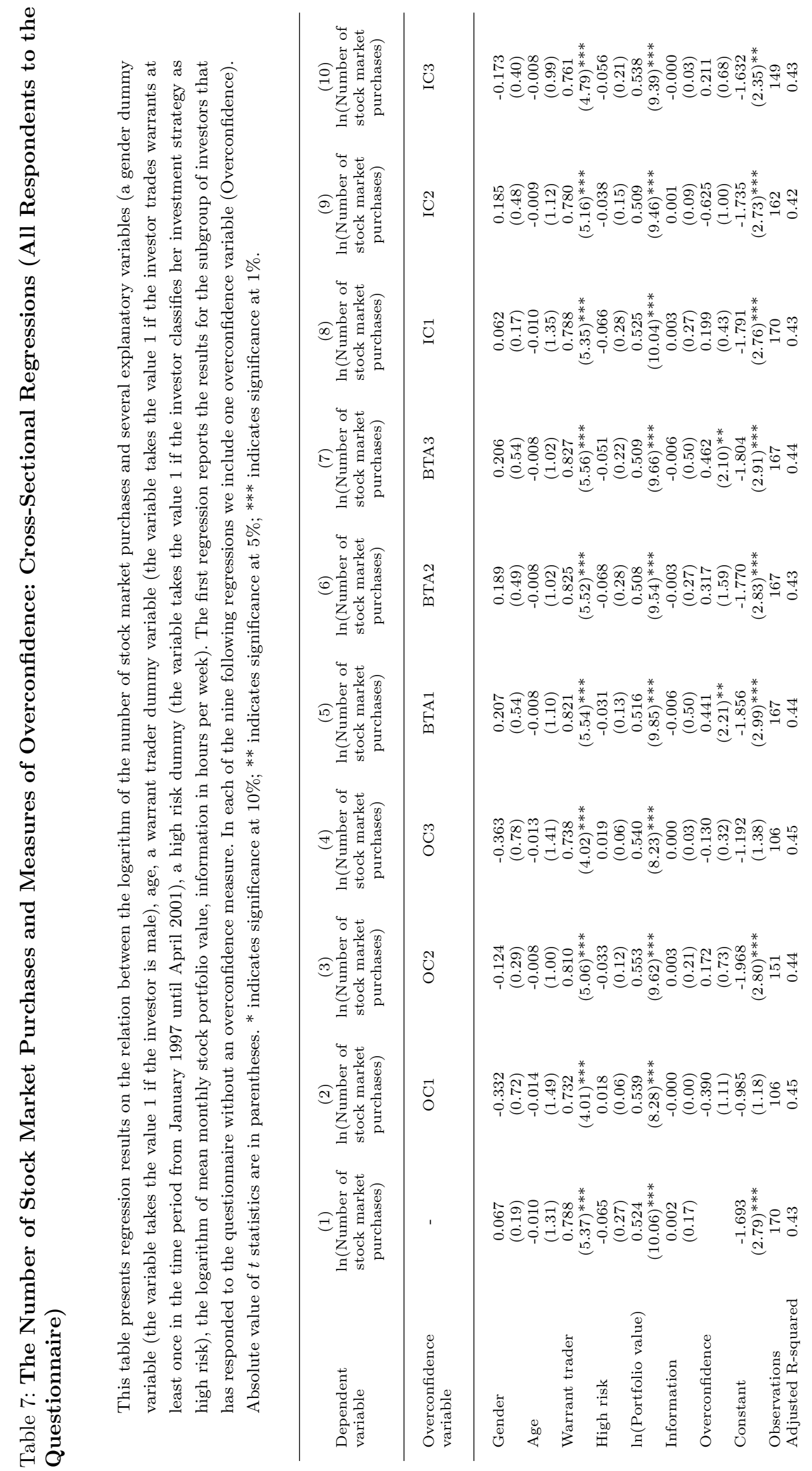




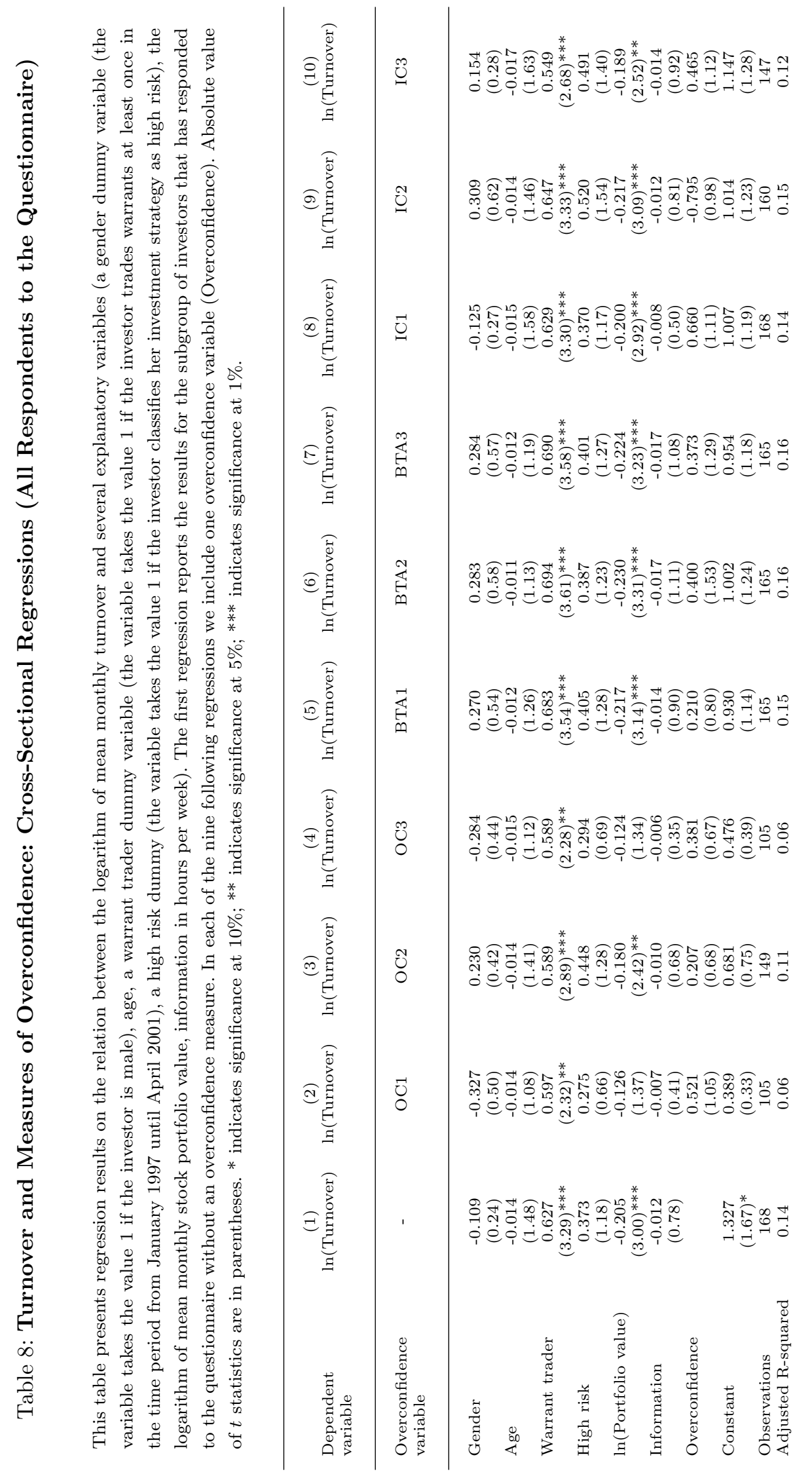




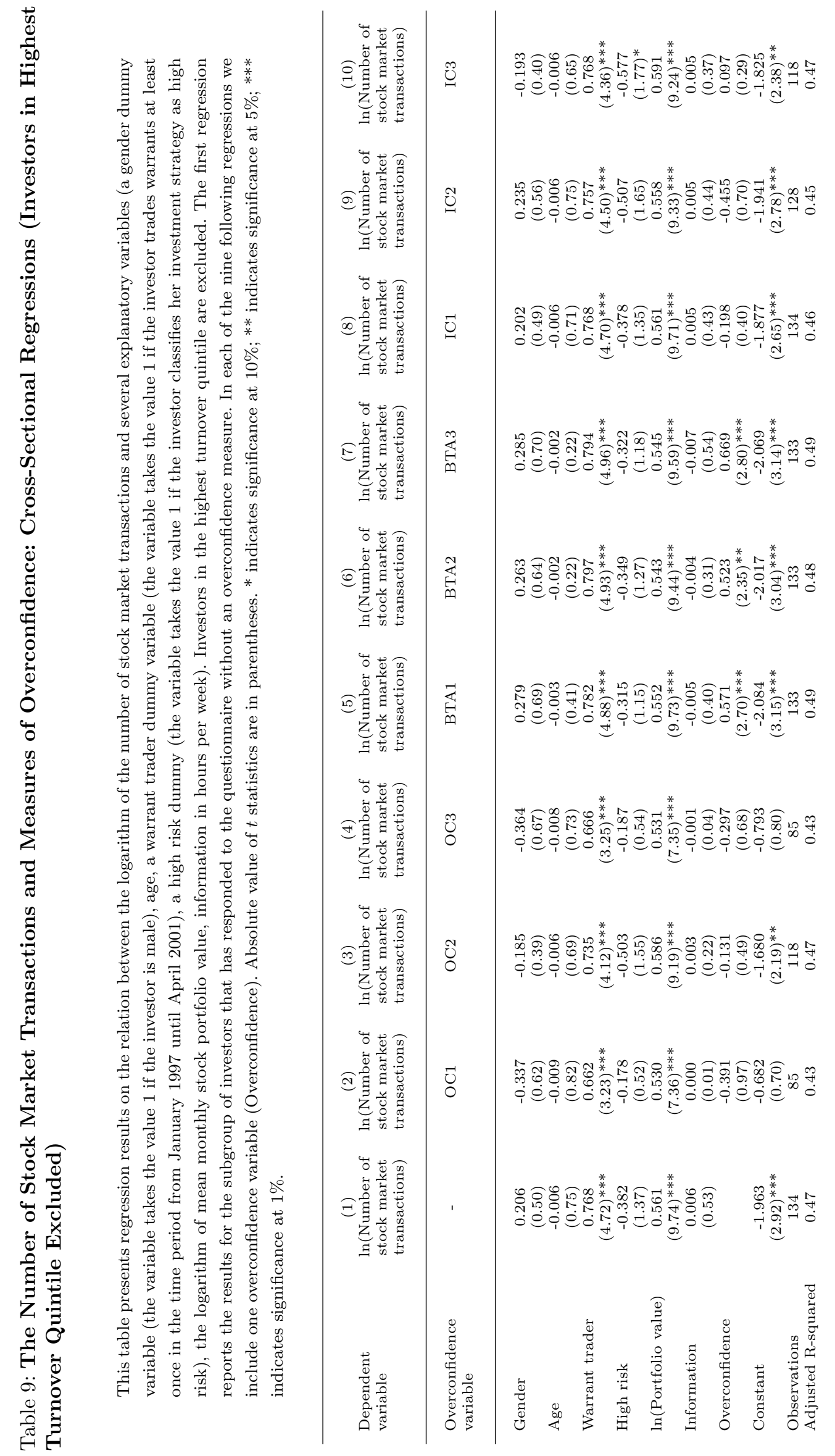




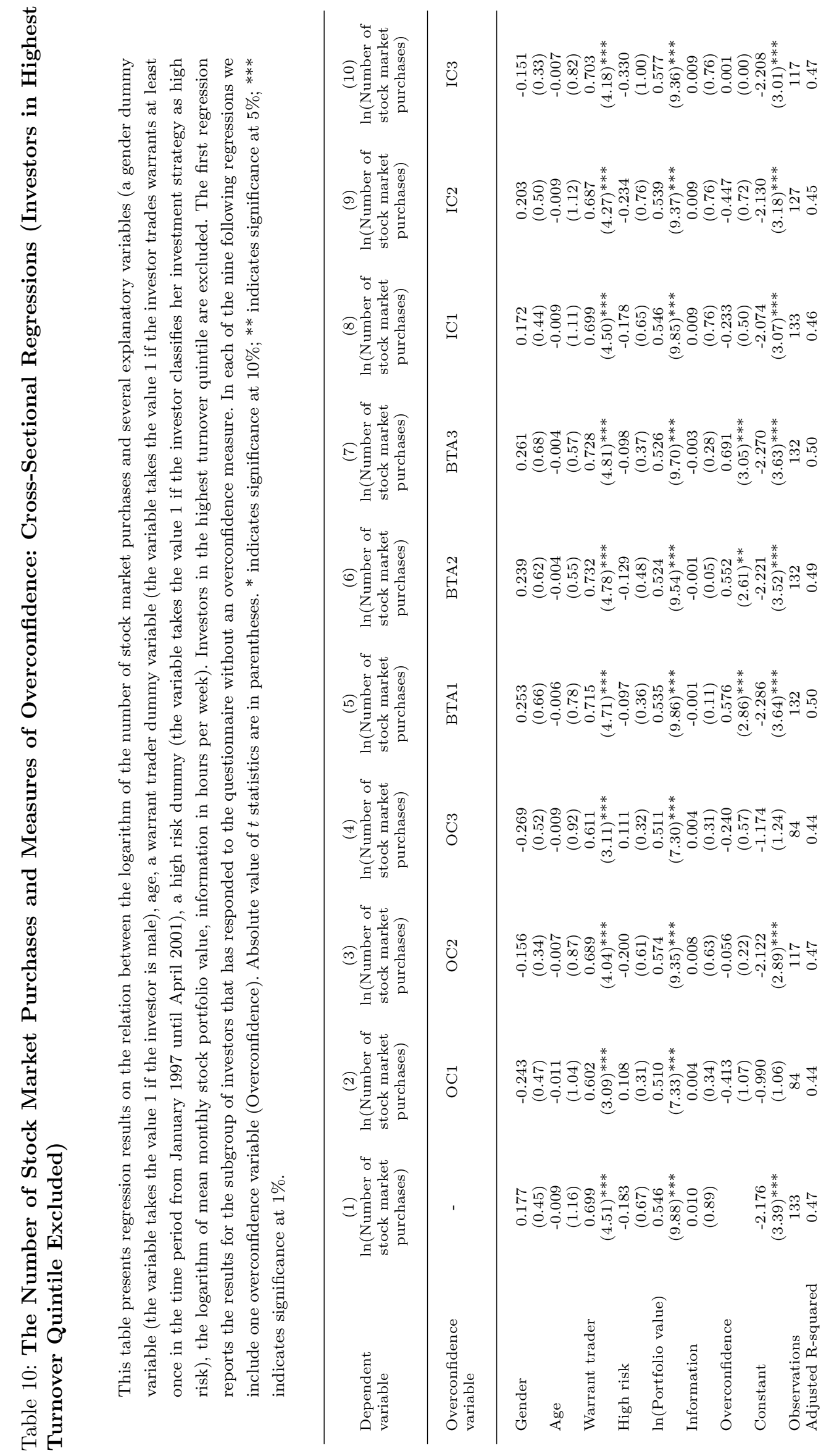




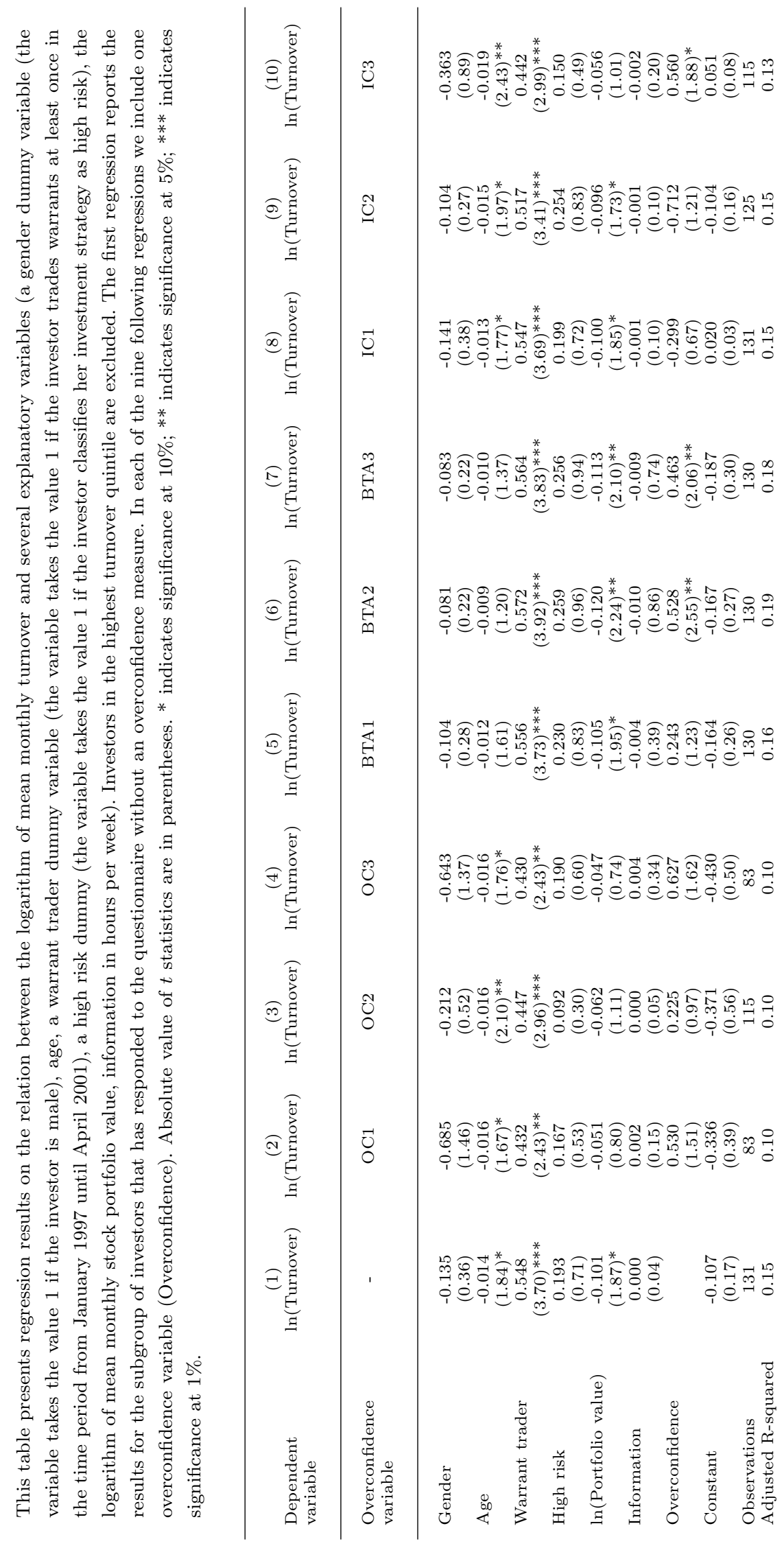




\section{Table 12: Cross-Sectional Distribution of Percentage Monthly Gross Portfolio Returns}

This table shows the cross-sectional distribution of the monthly gross returns of our investor sample. Gross monthly portfolio performance of each investor was calculated making the following simplifying assumptions: We assume that all stocks are bought and sold at the end of the month and we ignore intra-month trading. The gross portfolio return $R_{h t}^{g r}$ of investor $h$ in month $t$ is calculated as follows:

$$
R_{h t}^{g r}=\sum_{i=1}^{S_{h t}} w_{i h t} R_{i t} \quad \text { with } \quad w_{i h t}=\frac{P_{i t} n_{i h t}}{\sum_{i=1}^{S_{h t}} P_{i t} n_{i h t}}
$$

$R_{i t}$ is the return of stock $i$ in month $t, S_{h t}$ is the number of stocks held by individual $h$ in month $t$, $P_{i t}$ is the price of stock $i$ at the beginning of month $t$, and $n_{i h t}$ is the number of stocks of company $i$ held by investor $h$ in month $t$. $w_{i h t}$ is the beginning-of-month- $t$ market value of the holding of stock $i$ of investor $h$ divided by the beginning-of-month- $t$ market value of the whole stock portfolio of investor $h$. Time period is January 1997 to March 2001. Investors with 12 or less portfolio return observations are excluded from the sample. The table also shows the arithmetic monthly return of the German blue chip index DAX from January 1997 to March 2001 and the number of investors with more than 12 portfolio return observations in our 51 month sample period.

\begin{tabular}{lr}
\hline Mean & $0.54 \%$ \\
& \\
Minimum & $-16.02 \%$ \\
1st percentile & $-5.83 \%$ \\
5th percentile & $-2.99 \%$ \\
10th percentile & $-1.90 \%$ \\
25th percentile & $-0.49 \%$ \\
Median & $0.57 \%$ \\
75th percentile & $1.50 \%$ \\
90th percentile & $2.75 \%$ \\
95th percentile & $3.92 \%$ \\
99th percentile & $7.80 \%$ \\
Maximum & $23.81 \%$ \\
& \\
DAX (arithmetic monthly return) & $2.02 \%$ \\
Number of households & \\
& $2,793$ (91\% of 3,079$)$
\end{tabular}


Table 13: Summary of Findings

This table summarizes our findings on the correlation coefficients of our nine overconfidence measures and three measures of trading volume and the results of the cross-sectional regression analysis presented in the previous tables. ${ }^{*}$ indicates significance at $10 \% ; * *$ indicates significance at $5 \%$; *** indicates significance at $1 \%$.

\begin{tabular}{|c|c|c|c|c|c|c|c|}
\hline & & \multicolumn{3}{|c|}{ All respondents to the questionnaire } & \multicolumn{3}{|c|}{ Highest turnover quintile excluded } \\
\hline & & $\begin{array}{l}\ln (\text { Number of } \\
\text { stock market } \\
\text { transactions) }\end{array}$ & $\begin{array}{l}\ln (\text { Number of } \\
\text { stock market } \\
\text { purchases) }\end{array}$ & $\ln$ (Turnover) & $\begin{array}{l}\ln (\text { Number of } \\
\text { stock market } \\
\text { transactions) }\end{array}$ & $\begin{array}{c}\ln (\text { Number of } \\
\text { stock market } \\
\text { purchases) }\end{array}$ & $\ln$ (Turnover) \\
\hline \multirow{9}{*}{$\begin{array}{l}\text { Correlation } \\
\text { coefficients }\end{array}$} & OC1 & negative & negative & positive & negative & negative* & positive \\
\hline & $\mathrm{OC} 2$ & negative & negative & positive & negative & negative & positive \\
\hline & OC3 & negative & negative & positive & negative & negative & positive* \\
\hline & BTA1 & positive** & positive* & positive & positive*** & positive** & positive \\
\hline & BTA2 & positive* & positive* & positive & positive** & positive** & positive*** \\
\hline & BTA3 & positive** & positive* & positive & positive*** & positive** & positive** \\
\hline & IC1 & negative & negative & positive & negative & negative & negative \\
\hline & $\mathrm{IC} 2$ & negative & positive & negative & negative & positive & negative \\
\hline & IC3 & positive & positive & positive & positive & positive & positive \\
\hline \multirow{9}{*}{$\begin{array}{l}\text { Cross-sectional } \\
\text { regressions }\end{array}$} & OC1 & negative & negative & positive & negative & negative & positive \\
\hline & $\mathrm{OC} 2$ & positive & positive & positive & negative & negative & positive \\
\hline & OC3 & negative & negative & positive & negative & negative & positive \\
\hline & BTA1 & positive** & positive** & positive & positive*** & positive $* * *$ & positive \\
\hline & BTA2 & positive & positive & positive & positive** & positive** & positive** \\
\hline & BTA3 & positive* & positive** & positive & positive*** & positive $* * *$ & positive** \\
\hline & IC1 & positive & positive & positive & negative & negative & negative \\
\hline & $\mathrm{IC} 2$ & negative & negative & negative & negative & negative & negative \\
\hline & IC3 & positive & positive & positive & positive & positive & positive* \\
\hline
\end{tabular}


Figure 1: Monthly Gross Returns and Turnover

This figure presents the average gross monthly portfolio returns across investors for turnover quintiles. 1 indicates investors in the lowest turnover quintile, 5 indicates investors in the highest turnover quintile.

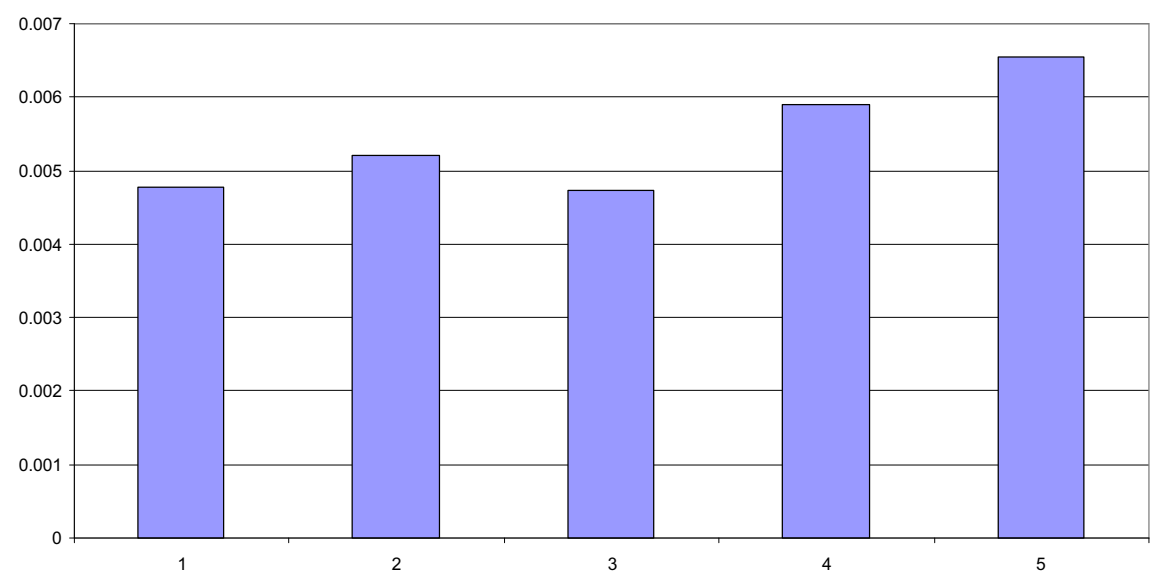

